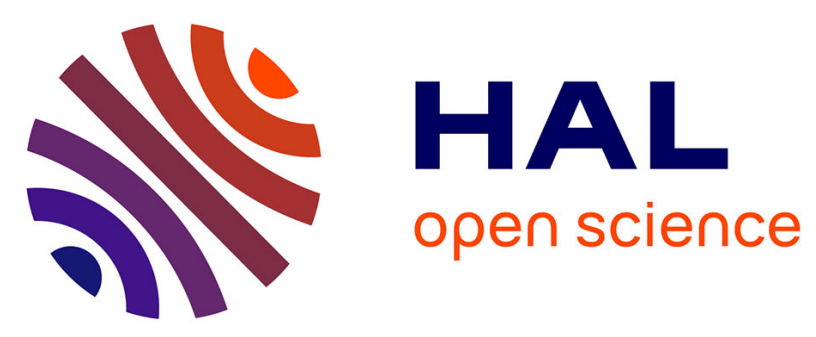

\title{
SiO 2 Biogenic Nanoparticles and Asphaltenes: Interactions and Their Consequences Investigated by QCR and GPC-ICP-HR-MS
}

Nelson Acevedo, Vicmary Vargas, Vincent Piscitelli, Aurélie Le Beulze, Brice Bouyssière, Hervé Carrier, Jimmy Castillo

\section{To cite this version:}

Nelson Acevedo, Vicmary Vargas, Vincent Piscitelli, Aurélie Le Beulze, Brice Bouyssière, et al.. SiO 2 Biogenic Nanoparticles and Asphaltenes: Interactions and Their Consequences Investigated by QCR and GPC-ICP-HR-MS. Energy \& Fuels, 2021, 35 (8), pp.6566-6575. 10.1021/acs.energyfuels.0c04185 . hal-03191454

\section{HAL Id: hal-03191454 \\ https://hal.science/hal-03191454}

Submitted on 7 Apr 2021

HAL is a multi-disciplinary open access archive for the deposit and dissemination of scientific research documents, whether they are published or not. The documents may come from teaching and research institutions in France or abroad, or from public or private research centers.
L'archive ouverte pluridisciplinaire HAL, est destinée au dépôt et à la diffusion de documents scientifiques de niveau recherche, publiés ou non, émanant des établissements d'enseignement et de recherche français ou étrangers, des laboratoires publics ou privés. 


\section{$\mathrm{SiO}_{2}$ Biogenic Nanoparticles and asphaltenes:}

\section{Interactions and their consequences investigated by}

\section{QCR and GPC-ICP-HR-MS}

Nelson Acevedo ${ }^{\prime 2}$, Vicmary Vargas $^{13}$, Vincent Piscitelli $^{\prime}$, Aurélie Le Beulze ${ }^{4}$, Brice Bouyssiere ${ }^{3}$, Hervé Carrierªnd Jimmy Castillo"

'Facultad de Ciencias, Escuela de Química, Universidad Central de Venezuela, 1041, Caracas, Venezuela

2Université de Pau et des Pays de l'Adour, E2S UPPA, CNRS, TOTAL, LFCR, Pau, France Université de Pau et des Pays de l'Adour, E2S UPPA, CNRS, IPREM, Institut des Sciences Analytiques et de Physico-chimie pour l'Environnement et les Matériaux, UMR5254, Hélioparc, 64053 Pau, France

${ }^{4}$ TOTAL S.E., CSTJF Research Center, 64018 Pau, France.

Keywords: Asphaltenes, Adsorption, Silica, Nanoparticles, Asphaltenes Aggregates, characterization, QCR, GPC-ICP-HR-MS 


\section{ABSTRACT}

The processes in which crude oil asphaltenes aggregates are adsorbed onto surfaces have been the subject of debate in recent years. Different thermodynamic, theoretical and empirical models have been proposed to explain the interaction of asphaltenes with these surfaces and have found different behaviors. In this work, asphaltene adsorption onto $\mathrm{SiO}_{2}$ biogenic nanoparticles was experimentally monitored by studying it through two analytical techniques, namely, Gel Permeation Chromatography coupled with Inductively Coupled Plasma and High Resolution Mass Spectrometry (GPC-ICP HR MS) to follow the changes in aggregates size distributions in solutions and a Quartz Crystal Resonator (QCR) sensor to detect and follow the destabilization with n-heptane, thus allowing the correlation of the different stabilities and deposition tendencies with the changes in aggregate size distributions. The results show that the nanoparticles interact in a preferential way with the larger asphaltene aggregates, and, once these large aggregates are adsorbed, there is no tendency for new large aggregate formation. Thus, a reduction in the deposition is observed. This indicates that, in this range of concentration, there is no equilibrium for aggregate formation and that these larger aggregates can be effectively removed. This finding opens new methodologies for study regarding asphaltene removal. 


\section{INTRODUCTION}

Asphaltenes are operationally defined as the fraction of crude oil insoluble in light $n$-alkanes (pentane-heptane) but soluble in benzene or toluene, and they represent the most polar and heaviest crude oil compounds '. Their structure and molecular mass are not well defined yet, not only due to the great polydispersity of molecules that constitute them but also because they vary according to the origin of the oil $^{2}$. However, an average molecular mass of $750 \mathrm{~g} \cdot \mathrm{mol}^{-1}$ and two dominant models of possible individual molecules for the asphaltenes structure, "island" (consisting of one polyaromatic core stabilized or not by a shell of alkyl side chains) and "archipelago" (consisting on multiple aromatic cores connected by small alkyl chains), are well accepted ${ }^{3}$. Recent studies have confirmed the coexistence of these two structures, with a prevalence of one over the other depending on the sample ${ }^{46}$.

The exploitation of heavy and extra-heavy oils fields is often problematic mainly due to their higher viscosity, requiring the use of diluents or high temperature conditions to reduce it. These hydrocarbon reserves are also those with higher percentage of asphaltenes and sulfur compounds. Changes in thermophysical properties that aim to improve the mobility of oils also modify their chemical properties and in particular their solvent power. These changes may result in asphaltene precipitation and deposition in reservoirs or production facilities, causing economical losses ${ }^{7-10}$.

The selective removal and fractionation of asphaltenes is required to produce homogeneous feedstock, making them easier to upgrade or use in other chemical industries ${ }^{3}$. For this purpose, the use of inhibitors that can prevent or delay asphaltene aggregation and deposition is a vast research field that goes from molecules, which can act as primary asphaltene dispersants or anti-flocculants ${ }^{11-17}$, to nanoparticles, which can adsorb asphaltenes and therefore inhibit their aggregation or deposition ${ }^{18-24}$. The use of nanoparticles can be advantageous over chemical inhibitors due to their easily tunable surface functionalities, high chemical and thermal stability 
in harsh conditions (high temperature, high salinity, high pressure, etc.), high specific surface (area-to-volume ratio), and in some cases, catalytic and magnetic properties ${ }^{2526}$. Silica-based nanoparticles are among those commonly used primarily due to their wide availability, wellcharacterized surfaces that are easily modified and used as catalyst supports, but above all, because they have a high affinity for asphaltene adsorption ${ }^{327}$.

Recent works have reported the use of different types of nanoparticles as asphaltene adsorbents ${ }^{2021282829}$. In many cases, these nanoparticles exhibit properties and functionalities higher than the macroscopic systems, although the adsorption mechanism is complex due to the competition of aggregation processes with adsorption on surfaces, this has made it difficult to discern between multilayer adsorption and aggregate adsorption. The mechanism is not fully understood and might be studied more. Nassar and collaborators present different thermodynamic models to explain this asphaltene adsorption process onto nanoparticles, and, in recent works, experimental data obtained can be fitted using simple models such as those based on the Langmuir theory, which considers only physical interaction with active sites, to more complicated models such as the Polanyi's modified theory or a theory based on chemical interaction to explain the adsorptive behavior ${ }^{303.1}$.

The complex nature of asphaltenes has been extensively researched, and their characterization has been the subject of many studies using different techniques. Recent results from techniques such as gel permeation chromatography inductively coupled plasma highresolution mass spectrometry (GPC ICP HR MS) and Fourier-transform ion cyclotron resonance mass spectrometry (FT-ICR-MS) demonstrate that asphaltenes are composed of lowmedium, medium, high and super high molecular weight fractions, meaning that, by nature, asphaltenes form families of aggregates of different hydrodynamic volumes in solution ${ }^{22-37}$. This result can have an important impact on the understanding of asphaltene adsorption processes and may be the key to discerning the dynamics of the process. 
Quartz crystal resonator sensors (also known as QCM) have been widely used for monitoring asphaltene flocculation and deposition processe $^{3-4-3}$ due to their high sensitivity (a few nanograms), fast response and versatility. The latter factor can be evidenced by the multiple setups that have been employed, from batch cells ${ }^{39,4244}$, flow cells ${ }^{40,4547}$ to high-pressure-hightemperature cells $s^{48,49}$, to evaluate the aggregation process in different conditions and thus have a better understanding of the process.

In the present work, $\mathrm{SiO}_{2}$ biogenic nanoparticles were used as the asphaltene sorbent. The resulting solutions were analyzed via GPC ICP HR MS and destabilized with n-heptane using a QCR sensor to follow the aggregation and deposition processes of unstable asphaltenes. Results show that the asphaltenes larger aggregates distributions (sHMW and HMW) have a dominant role in the stability and deposition characteristics compared to the smallest aggregates distributions (MMW and LMW). These results open the development of alternatives methodologies to minimize asphaltene aggregation and deposition.

\section{EXPERIMENTAL SECTION}

Chemicals and Materials. Venezuelan heavy crude oil, Cerro Negro (API= 8, asphaltene content of $8 \mathrm{wt} \%$, Vanadium content of $1340 \mathrm{mg} . \mathrm{Kg}^{-1}$ and Sulfur content of 5,64 wt\%), was used for obtaining $\mathrm{C}_{7}$ asphaltenes. Toluene (>99.8\%) and n-heptane (>99\%) were acquired from Fisher Scientific, while tetrahydrofuran (THF) (99.5\%) was acquired from Scharlau. They were used as received, without further purification.

Asphaltene precipitation. Asphaltenes (Asph) precipitation was carried out according to the ASTM D 6560/IP 143 standard, as reported before ${ }^{32}$, mixing approximately $40 \mathrm{~mL}$ of $\mathrm{n}$-heptane per gram of crude oil. The mixture was stored in darkness and at room temperature for $48 \mathrm{~h}$. 
The precipitate was collected by vacuum filtration on Whatman (grade 42) filter paper and rinsed with n-heptane. The solid was then subjected to a Soxhlet extraction with boiling nheptane until complete transparency of the liquid was achieved. The solid was dried in vacuum at $40^{\circ} \mathrm{C}$ for $48 \mathrm{~h}$.

Biogenic $\mathrm{SiO}_{2}$ Nanoparticle Synthesis. Biogenic silica nanoparticles (Nps) were synthetized from rice husks using a calcination method previously reported by Castillo et al ${ }^{50}$. In brief, prewashed rice husks were lixiviated with hydrochloric acid for $24 \mathrm{~h}$ and washed with water until a neutral $\mathrm{pH}$ was measured. The rinsed rice husks were dried in an oven at $110^{\circ} \mathrm{C}$ for $3 \mathrm{~h}$, and then the temperature was raised to $700^{\circ} \mathrm{C}$ for $6 \mathrm{~h}$. Finally, Nps were obtained after $12 \mathrm{~h}$ of grinding in a ball mill. The average size of the Nps, measured by dynamic light scattering, and the specific surface, measured by BET, are shown in Table 1.

Table 1 - Physical characteristics of $\mathrm{SiO}_{2}$ biogenic nanoparticles.

\begin{tabular}{cc}
\hline Mean hydrodynamic diameter $(\mathbf{n m})$ & Specific surface $(\mathbf{B E T})\left(\mathbf{m}^{2} \cdot \mathbf{g}^{-1}\right)$ \\
\hline $\mathbf{4 0}$ & 234 \\
\hline
\end{tabular}

Asphaltenes adsorption experiments. Dried asphaltenes were dissolved in toluene, providing a $600-\mathrm{mg} / \mathrm{l}$ stock solution. This solution was stored in the dark and at room temperature for $24 \mathrm{~h}$. After this time, $25-\mathrm{mL}$ aliquots of this solution (containing $15 \mathrm{mg}$ of asphaltenes) were added to 7 vials containing different amounts of Nps from 0 to $1050 \mathrm{mg}$, as shown in Table 2. The mixture was placed in ultrasound for 5 minutes before storing in the dark and at temperature for 72 hours. 
GPC ICP HR MS Measurements. Nanoparticles were separated from the liquid via centrifugation at $6000 \mathrm{rpm}$ for $15 \mathrm{~min}$ at constant temperature $\left(25^{\circ} \mathrm{C}\right)$. From the supernatant solutions, $1.5-\mathrm{mL}$ aliquots were placed in an open vial and the toluene was evaporated to dryness. Solid asphaltenes were dissolved in $1.5 \mathrm{~mL}$ of THF and analyzed using GPC-ICP HR MS. For each sample, $20 \mu \mathrm{L}$ was injected and eluted isocratically at a flow rate of $1 \mathrm{~mL} \cdot \mathrm{min}^{-1}$ of THF for 120 min using a Dionex (Amsterdam, The Netherlands) HPLC system consisting of an UltiMate 3000 microflow pump, an UltiMate 3000 autosampler, and a low port-to-port dead-volume microinjection valve. A post-column splitter was used to divide the flow (20:1). The low-flow outlet (50 $\mu \mathrm{L} / \mathrm{min}$ ) led to the ICP-HRMS using a DS-5 microflow (CETAC, Omaha, NE), and the high-flow outlet $(950 \mu \mathrm{L} / \mathrm{min})$ was sent to the UV-Visible spectrometer.

A Thermo Scientific Element XR sector field ICP-HRMS instrument operating at a resolution of 4000 (medium resolution) was used to access spectrally interfering isotopes of ${ }^{60} \mathrm{Ni}{ }^{3} \mathrm{~S}$ and ${ }^{5} \mathrm{~V}$. An $\mathrm{O}_{2}$ flow was continuously supplied to the nebulizer Ar gas flow. The ICP-HR MS was fitted with a modified DS-5 microflow total consumption nebulizer mounted on a laboratorymade, low-volume (8-mL), single-pass jacketed glass spray chamber without a drain, as described elsewhere ${ }^{51,52}$. The spray chamber was set to $60^{\circ} \mathrm{C}$ with a thermostat.

Separations were conducted using three Styragel styrenedivinylbenzene gel permeation columns connected in series $(7.8 \times 300 \mathrm{~mm}$ ). These columns were HR4 (particle size, $5 \mu \mathrm{m}$; exclusion limit, $600000 \mathrm{Da}$ of polystyrene [PS] equivalent), HR2 (particle size, $5 \mu \mathrm{m}$; exclusion

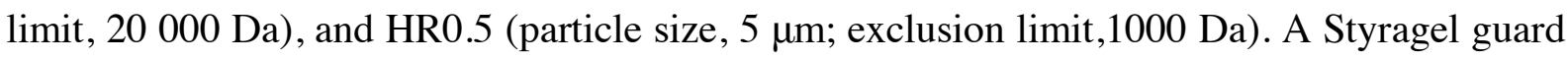
column $(4.6 \times 30 \mathrm{~mm})$ was included before these three columns to protect them and prolong their lifetimes. A calibration of the columns with polystyrene standards (PS) was done and is shown in the Supporting Information SI.1.

The column calibration was only used to verify the performance of the columns and not to determine the MW of the asphaltenes, due to the difference in complexity between the polymer 
standards and asphaltene's matrix. However, in our previous publications we have shown that HMW size distribution are primarily aggregate compounds, while LMW are "free" compounds, and MMW a mixture of "free" and aggregate compounds ${ }^{343637}$.

The ICP-HR MS conditions were controlled and optimized daily using a $1.0 \mathrm{ng}^{\mathrm{g}}{ }^{-1}$ multielement (V, Ni, S and Fe) tuning solution in THF delivered via a syringe pump. The detailed experimental setup, conditions and procedure can be found in our previous work ${ }^{32}$.

The measurements of all samples were carried out once, and during the measurement sequence, a control asphaltenes solution was intercalated three times between the samples in the sequence to verify that the intensity and the profile distribution remained constant. The control sample presented a reproducible profile with an RSD below $1 \%$ within these 3 injections.

UV analysis. The concentrations of remnant solutions were obtained by measuring the absorbance spectra with an UV spectrophotometer Mettler- Toledo (UV7) using a $1 \mathrm{~cm}$ quartz cell and scanning from 190 to $1100 \mathrm{~nm}$.

QCR Titration experiments. Equal amounts (22 g) of the remnant solutions were destabilized employing $\mathrm{n}$-heptane as the flocculating agent. The aggregation and deposition process were monitored using a fully immersed QCR sensor, the setup of which is shown in Figure 1. The quartz crystal sensor was put inside the custom double-wall vessel at a constant temperature of $30^{\circ} \mathrm{C}$, the temperature at which all the titration experiments reported in this article were carried out. A computer with a LabVIEW internally automated program was used for controlling a network analyzer Agilent E5071C for transmitting electrical signals and monitoring the QCR sensor response. The sensor was allowed to stabilize, which corresponds to frequency changes of less than $0.5 \mathrm{~Hz}$, and the frequencies in air (background) were recorded. The sample solution was placed in the cell, and the system was left for approximately 30 min to reach a stable signal. The titration was carried out with n-heptane pumped at a constant speed 
of $0.25 \mathrm{~g} / \mathrm{min}$, and the mixture in the vessel was stirred at a constant rate using a magnetic bar stirrer. The titration was finished once $80 \mathrm{wt} . \%$ n-heptane was reached.
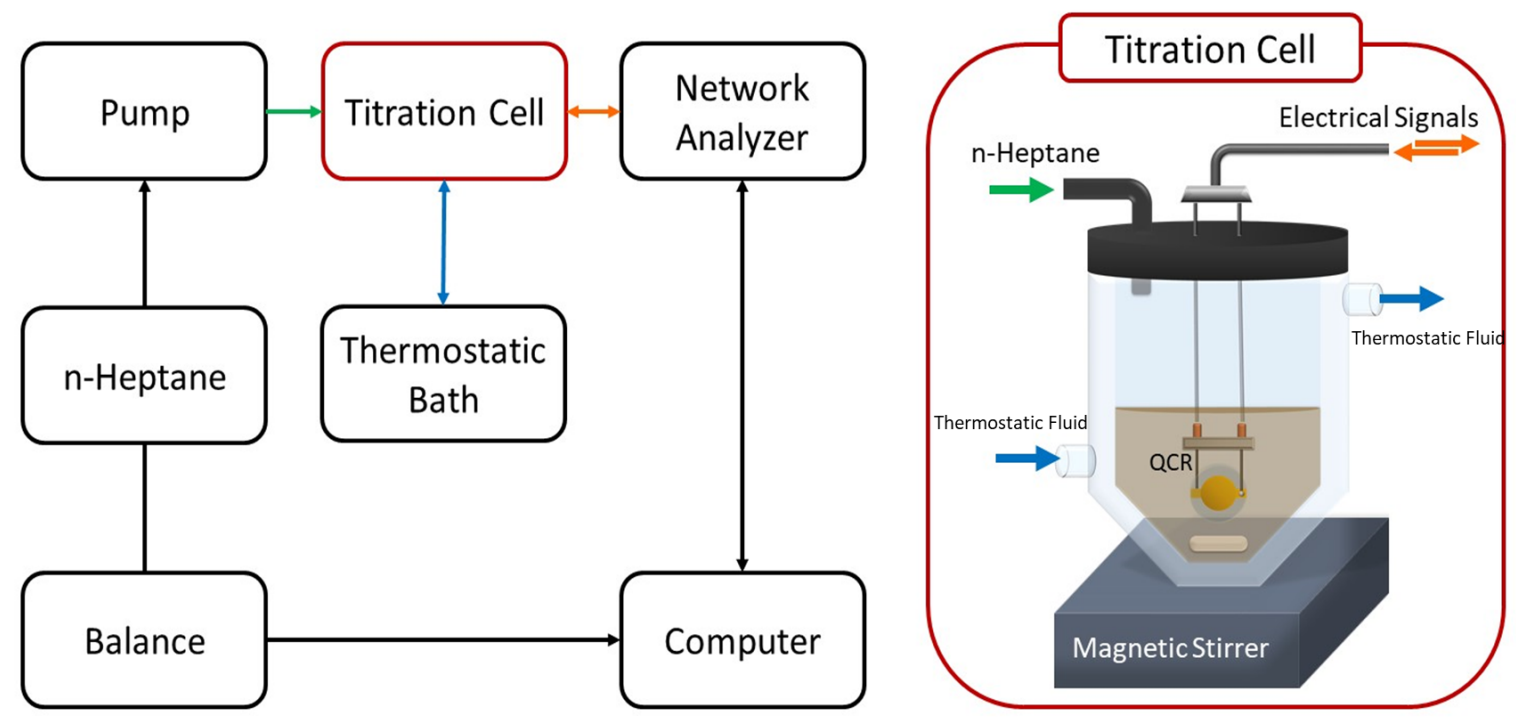

Figure 1. Experimental setup for n-heptane titration followed by the QCR sensor

The sensor consists of a polished AT-cut quartz crystal disc with 100-nm layers of gold as electrodes on each face and a 3-MHz nominal frequency. Frequency shifts $(\Delta \mathrm{f})$ were calculated by subtracting the frequency in air and the frequency in the sample of the $\mathrm{n}^{\mathrm{th}}$ harmonic during the titration process every $2 \mathrm{~min}$.

During titration, $\mathrm{n}$-heptane is progressively added, changing the properties of the medium and inducing asphaltene destabilization leading to aggregation and deposition. These phenomena can be correlated with changes in the oscillation parameters of the sensor. Using a simple mathematical model, frequency and dissipation shifts ( $\Delta \mathrm{f}$ and $\Delta \Gamma$, respectively), can be used for determining the destabilization onset and the theoretical mass deposited on the quartz surface.

$$
\Delta f_{n}=-n\left(2 C_{m} \Delta m\right)-\sqrt{n} \frac{C_{m}}{\sqrt{\pi f_{0}}} \sqrt{\rho \eta} \quad \text { Eq. } 1
$$


$\Delta \Gamma_{n}=\sqrt{n} \frac{C_{m}}{\sqrt{\pi f_{0}}} \sqrt{\rho \eta}(1+R)$ Eq. 2

Here, $\mathrm{Cm}$ is a constant that depends on the crystal characteristics, $\Delta \mathrm{m}$ is the theoretical mass deposited on the quartz surface, $\rho \eta$ is the density-viscosity product of the medium, $\mathrm{f}_{0}$ is the fundamental resonance frequency of the crystal, and $\mathrm{R}$ is an empirical correction term that accounts for viscous friction on rough surfaces ${ }^{48}$. 


\section{RESULTS}

\section{QCR Titration.}

An example (Sample A) of the data obtained on the titration of the asphaltenes solutions is shown in Figure 2. Frequency shifts $\left(\Delta f_{n}=-n\left(2 C_{m} \Delta m\right)-\sqrt{n} \frac{C_{m}}{\sqrt{\pi f_{0}}} \sqrt{\rho \eta} \quad\right.$ Eq. 1) are related to both mass loading (first term) and liquid loading effects (second term), while dissipation shifts $\left(\Delta \Gamma_{n}=\sqrt{n} \frac{C_{m}}{\sqrt{\pi f_{0}}} \sqrt{\rho \eta}(1+R) \quad\right.$ Eq. 2) are related only to liquid loading effects. Thus, plotting the frequency shift as function of the dissipation shift (Figure 2a) allows estimation of the occurrence of the mass loading effect as a deviation from linear behavior (red dashed line). For the samples analyzed, this mass loading is related to the interaction of asphaltene particles with the quartz sensor, meaning that the composition at which this deviation occurs can be denoted as the destabilization onset (DO) of the asphaltenes (Figure 2b).

Before DO (light blue), there is a positive $\Delta \mathrm{f}$ due to the decrease of the $\rho \eta$ of the surrounding media. After DO (blue-gray zone), the destabilization of asphaltenes occurs, and flocculation and aggregation processes start. This phenomenon is taken into account in the first term of Eq. 1 ; thus, a change in the slope is observed, but still positive, due to the prevalence of the decrease of the $\rho \eta$ of the surrounding media. The purple zone, denoted by the prevalence of mass loading effects over the reduction of the $\rho \eta$, is where asphaltene aggregation and deposition are easily observed in Figure $2 \mathrm{c}$ and Figure 2d. The curves for the rest of the samples $(\mathrm{B}-\mathrm{H})$ can be found in the Supporting Information SI.3. 

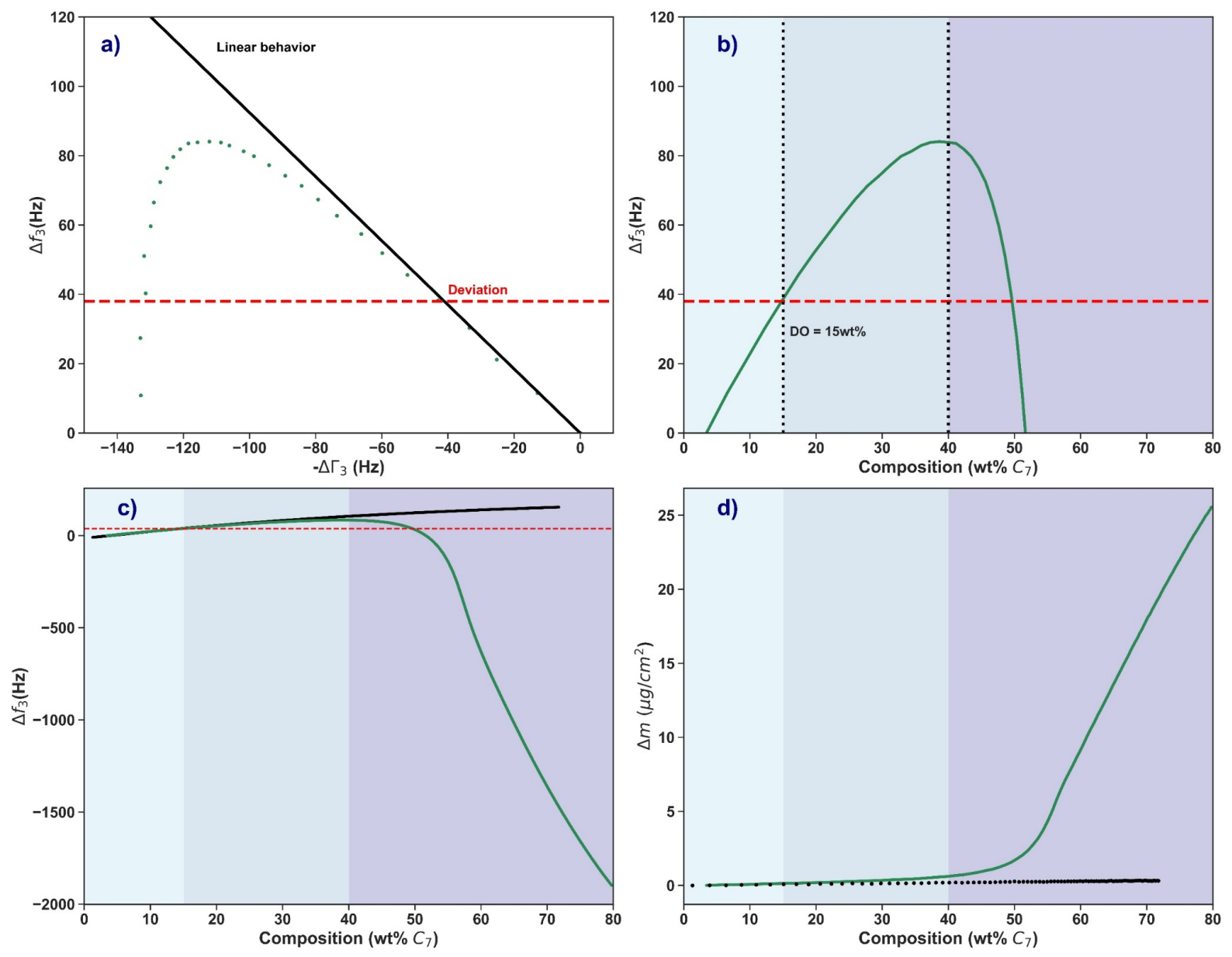

Figure 2. n-Heptane titration of asphaltenes (Sample A) followed by the QCR sensor at $30^{\circ} \mathrm{C}$.

a) $\Delta f_{3}$ vs $\Delta \Gamma_{3}$. b) Destabilization Onset (DO) estimation. c) Frequency shifts of the $3^{\text {w }}$ harmonic $\left(\Delta \mathrm{f}_{3}\right)$ as a function of composition. d) Theoretical deposited mass $(\Delta \mathrm{m})$ as a function of composition. Light blue area represents the stable zone with mass loading effect $=0$. Blue-gray area represents the unstable zone, with mass loading effect < liquid loading effect. The purple area represents the unstable zone with mass loading effect $>$ liquid loading effect.

The theoretical deposited mass (Figure 2dErreur ! Source du renvoi introuvable.) was determined by analyzing the $3^{\text {rd }}, 5^{\mathrm{th}}, 7^{\mathrm{th}}$ and $9^{\mathrm{th}}$ harmonics and plotting the linear relation of Eq. 1 . Details can be found in our most recent publication ${ }^{43}$.

The destabilization onset and theoretical deposited mass for all the samples are listed in Table 2, where it can be noted that the destabilization onset of pure asphaltenes (sample A) was found 
to be $15 \mathrm{wt} \%$ of n-heptane. In contrast, for Nps-treated samples (samples B-H), the stability of the solution increased with the increase of NAMR. It is also clear that samples F-H do not form enough deposit (less than $\left.0.5 \mu \mathrm{g} / \mathrm{cm}^{2}\right)$ compared to samples A-E (3-25 $\left.\mu \mathrm{g} / \mathrm{cm}^{2}\right)$ suggesting a complete adsorption of the unstable asphaltenes (at $80 \mathrm{w} \%$ of n-heptane composition) by the biogenic silica nanoparticles after NARM $=20$.

Table 2. Samples mass compositions and destabilization characteristics of remnants solutions determined with the QCR sensor.

\begin{tabular}{|c|c|c|c|c|c|c|}
\hline \multirow[b]{2}{*}{ Sample } & \multicolumn{2}{|c|}{$\begin{array}{c}\text { Mass } \\
\text { Compositions }\end{array}$} & \multicolumn{4}{|c|}{ Remanants solution } \\
\hline & $\begin{array}{l}\text { Nps } \\
\text { mass } \\
(\mathrm{mg} \\
\pm 1 \\
\mathrm{mg})\end{array}$ & NAMR & $\begin{array}{c}\text { Total } \\
\text { Concentration* } \\
(\mathrm{mg} / \mathrm{l})\end{array}$ & $\begin{array}{c}\text { V } \\
\text { Concentration }^{*} \\
(\mathrm{mg} / \mathrm{Kg})\end{array}$ & $\begin{array}{c}\text { Destabilization } \\
\text { Onset } \\
\text { (wt\% n- } \\
\text { heptane) }\end{array}$ & $\begin{array}{c}\text { Deposited } \\
\text { Mass } \\
(\Delta \mathrm{m}) \\
\left(\mu \mathrm{g} . \mathrm{cm}^{-2}\right)\end{array}$ \\
\hline $\mathrm{A}$ & 0 & 0 & 604 & 2057 & 15 & 25.6 \\
\hline B & 30 & 2 & 508 & 1879 & 16 & 21.0 \\
\hline $\mathrm{C}$ & 75 & 5 & 361 & 1465 & 17 & 16.0 \\
\hline $\mathrm{D}$ & 150 & 10 & 220 & 1140 & 18 & 9.3 \\
\hline $\mathrm{E}$ & 225 & 15 & 146 & 926 & 20 & 3.3 \\
\hline $\mathrm{F}$ & 300 & 20 & 96 & 672 & 22 & 0.4 \\
\hline $\mathrm{G}$ & 450 & 30 & 51 & 497 & 49 & 0.0 \\
\hline $\mathrm{H}$ & 1050 & 70 & 33 & 377 & 66 & 0.0 \\
\hline
\end{tabular}

$\S$ Nanoparticles/ Asphaltenes Mass Ratio *Obtained via UV-Vis before titration $¥$ Calculated from the GPC-ICP MS profile area and using a V concentration of $2057 \mathrm{mg}$.Kg-1 reported by Marcano et al. ${ }^{s 3}$ for this asphaltenes sample.

As samples F-H have very low concentrations $(<100 \mathrm{mg} / \mathrm{l})$, the low deposition detected could be attributed with the low amount of asphaltenes and not to the absence of unstable asphaltenes. To verify this, a titration experiment was performed on a diluted asphaltene solution $(30 \mathrm{mg} / \mathrm{l})$, 
and the results are shown in Figure 3. Analysis of this figure clearly establishes that, even at a very low concentration $(30 \mathrm{mg} / \mathrm{l})$, the quartz can detect the destabilization onset, and this sample presented the same destabilization onset (15 wt $\%$ ) as pure asphaltenes (Figure 3-b). Concerning the deposition (Figure 3-c), $30 \mathrm{mg} / \mathrm{l}$ solution still presented adsorption onto the quartz (3.5 $\left.\mu \mathrm{g} . \mathrm{cm}^{-2}\right)$ compared to that obtained for samples $\mathrm{F}$ and $\mathrm{G}\left(0.4\right.$ and $\left.0 \mu \mathrm{g} . \mathrm{cm}^{-2}\right)$, which suggests that nanoparticles effectively adsorb the part of the asphaltenes that is responsible for the destabilization and deposition phenomena.
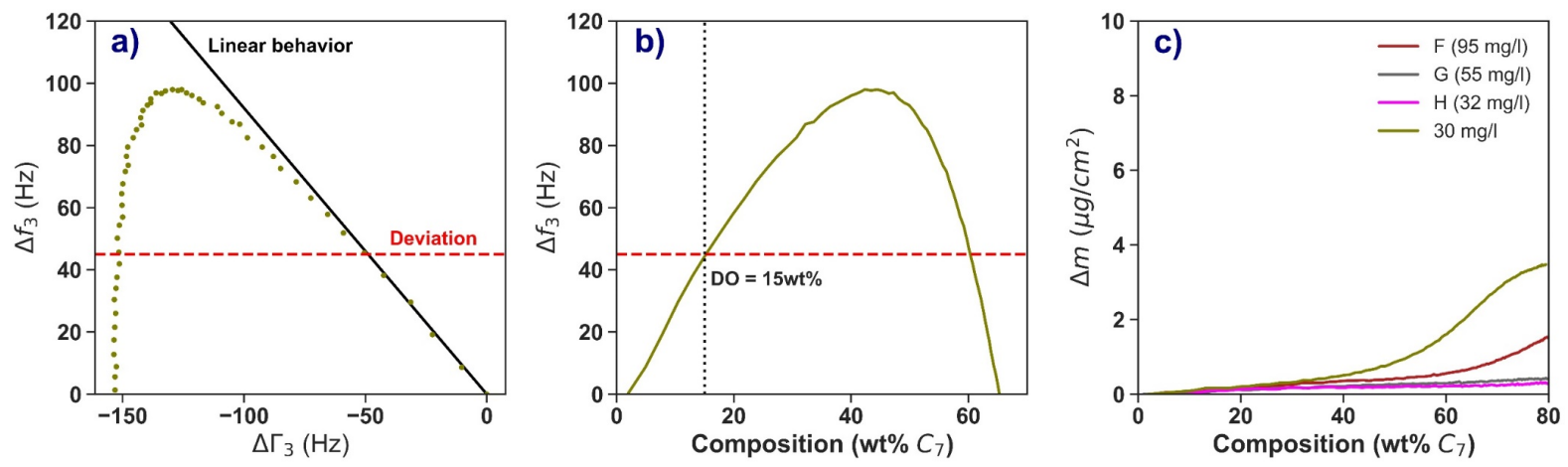

Figure 3. n-Heptane titration of diluted asphaltenes $(30 \mathrm{mg} / \mathrm{l})$ followed by the QCR sensor at $30^{\circ} \mathrm{C}$. A) $\Delta \mathrm{f}_{3}$ vs $\Delta \Gamma_{3}$. B) Destabilization onset (DO) estimation. C) Theoretical deposited mass comparison with samples A, F and G.

GPC-ICP-HR-MS Measurements. ${ }^{32}$ Sulfur- (a) and ${ }^{51}$ Vanadium-containing compounds (b) chromatograms of the samples after the adsorption onto Nps are presented in Figure 4. A progressive reduction of the signal is observed compared to the pure asphaltenes sample (A) in the whole profile for the 5 first samples $(B-G)$ with NAMR $<30$. A different profile is obtained for samples $\mathrm{G}$ and $\mathrm{H}(\mathrm{NAMR}=30$ and 70$)$; the signals between 1000-1260 s are no longer present. The aggregate size distributions were defined as super-high molecular weight (sHMW), high molecular weight (HMW), medium molecular weight (MMW) and low 
molecular weight (LMW) with ranges in time of 950-1250 s, 1140-1530 s, 1280-1820 s and $1600-1860$ s, respectively
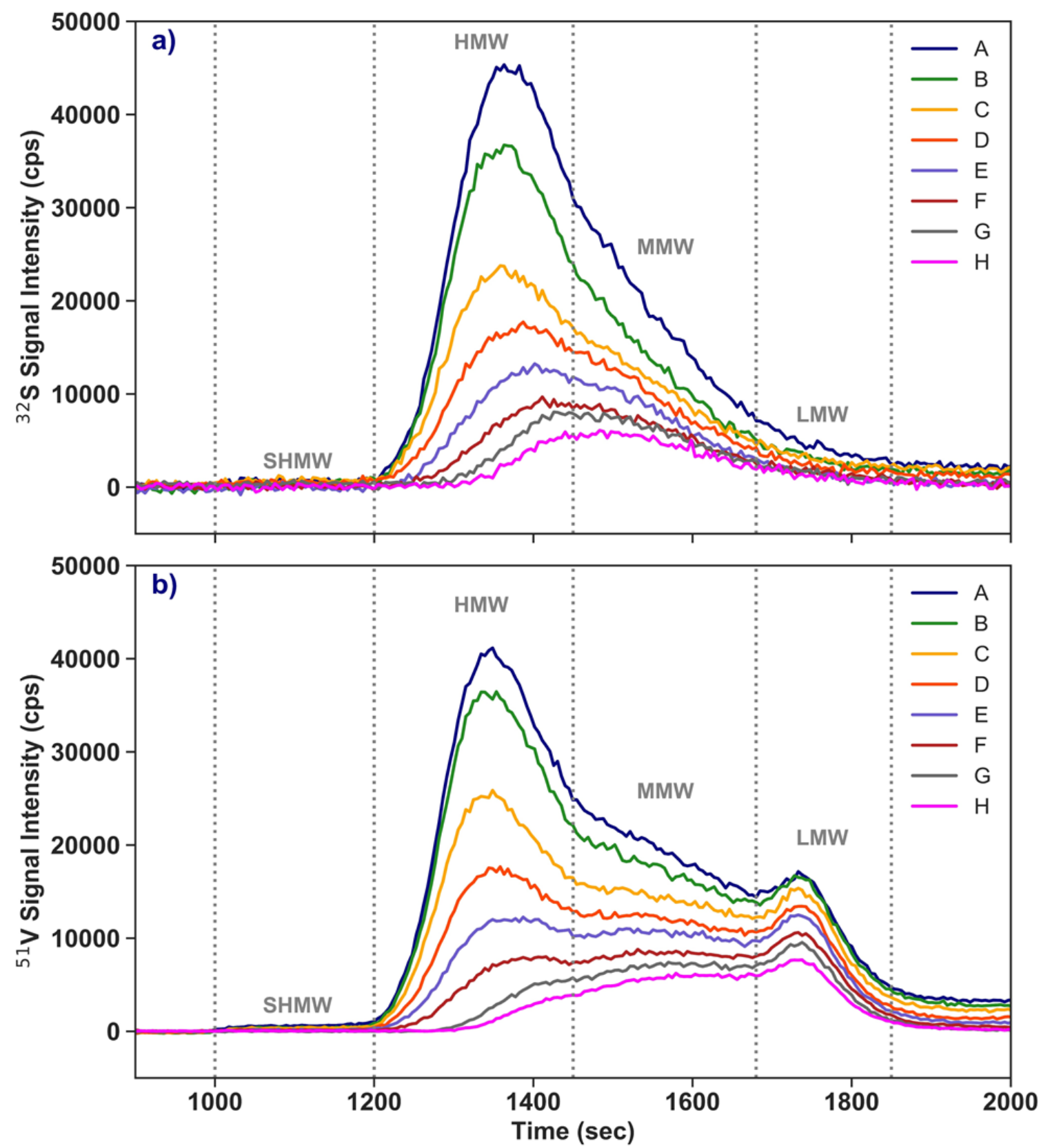

Figure 4. Sulfur- (a) and Vanadium-containing (b) compounds GPC-ICP HR MS chromatograms for asphaltenes solutions before (A) and after (B-H) adsorption onto $\mathrm{SiO}_{2}$ Bionanoparticles. sHMW, HMW, MMW, and LMW size distributions are separate by grey dashed lines. 
It has been recently reported for Stöber-synthetized $\mathrm{SiO}_{2}$ nanoparticles ${ }^{32}$ and also for $\mathrm{SiO}_{2}$ biogenic nanoparticles ${ }^{50}$ that asphaltene aggregates of higher molecular weights present stronger interactions with them due to Van der Waals forces. To verify this, a Gaussian fit was made, decomposing the signal into the four aggregates size distributions, based on the minimum observed in the profile. Complete explanation for the gaussians choice for the signal decomposition can be found in the Supporting Information SI.4. Figure 5 shows an example of the Gaussian fit for Samples A and $\mathrm{H}$ (for the rest of the samples, see the Supporting Information SI.4), where it can be noted that HMW size distribution is composed by two families, denoted $\mathrm{HMW}_{1}$ and $\mathrm{HMW}_{2}$, while MMW size distribution is composed by three $\left(\mathrm{MMW}_{1}, \mathrm{MMW}_{2}, \mathrm{MMW}_{3}\right)$. The efficacy of the decomposition treatment can be noted in the almost perfect fit of the sum of the Gaussian functions (red dashed line) to the sample signal (dark solid line).
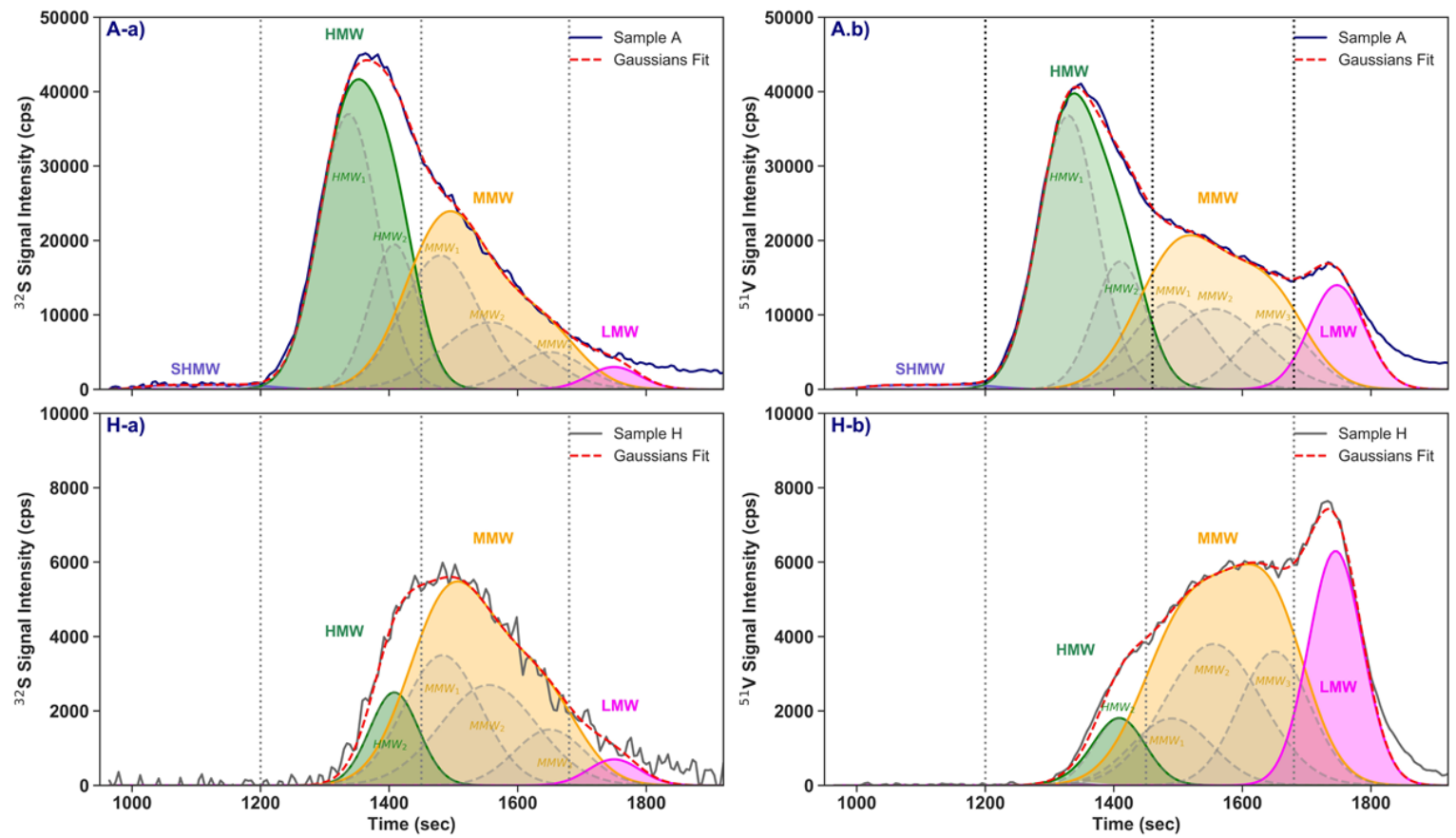

Figure 5. Gaussians fit and decomposition into four size distributions (sHMW, HMW, MMW and LMW) of GPC-ICP-HR-MS (a) Sulfur- and (b) Vanadium-containing compounds chromatograms for Sample A (upper panel) and Sample H (lower panel). Vertical dotted lines define the border of the corresponding size distribution. 
This decomposition treatment allows calculation of the area under the curve for each size distribution and thus makes a clear evolution of each distribution in the adsorption, as shown in Figure 6. The disappearance of sHMW and HMW, compounds after samples D and F (NAMR $=15$ and 20, respectively), confirms the previous assessment that $\mathrm{SiO}_{2}$ nanoparticles interact preferably with larger nanoaggregates.

a)

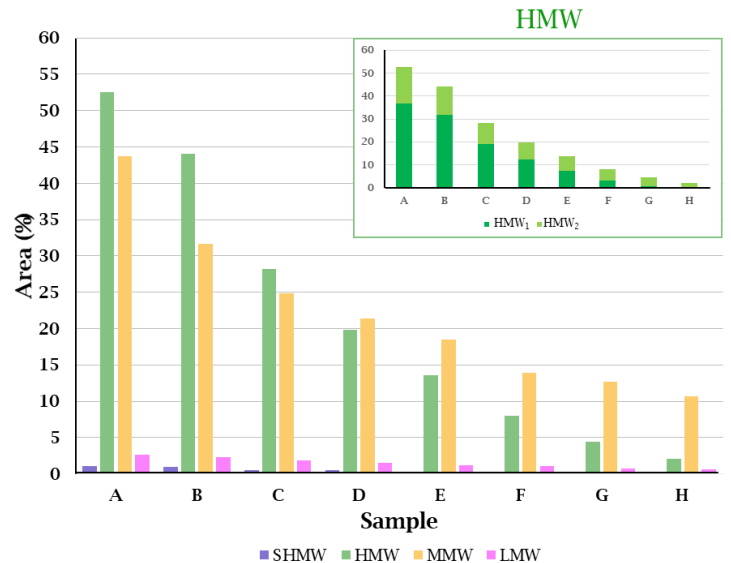

b)

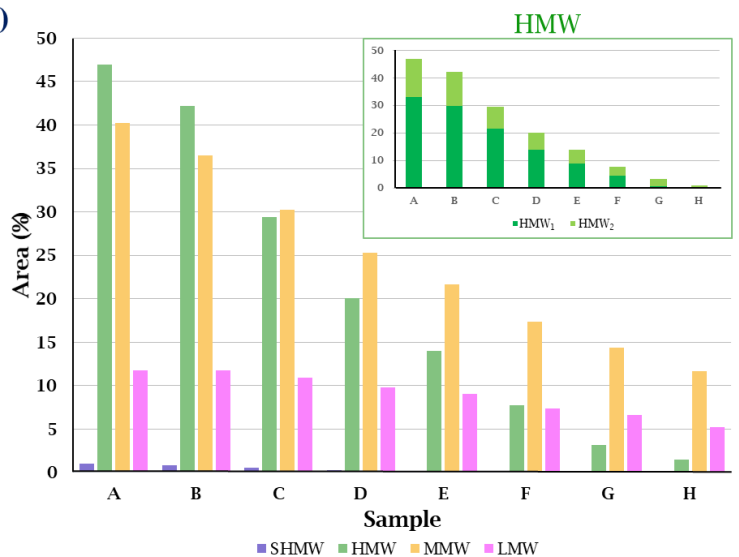

Figure 6. Aggregates size distribution areas of ${ }^{32}$ Sulfur- (a) and ${ }^{51}$ Vanadium containing compounds (b) obtained with the gaussian fitting for all samples. The green plot at the upper right panel, represent the variation of the two HMW families $\left(\mathrm{HMW}_{1}\right.$ and $\left.\mathrm{HMW}_{2}\right)$. Areas for samples B-H are calculated respect to the total area of sample A.

The Gaussian fitting treatment shows that the sHMW and the main part of the HMW compounds, the HMW, family, are completely adsorbed while only a small fraction of the MMW and LMW compounds are adsorbed. It has been recently ${ }^{37}$ reported that "free" porphyrins eluted in the LMW range, thus the low reduction of this size distribution observed in Figure 6.b suggests that's these compounds do not interact strongly with the nanoparticles.

\section{DISCUSSION}

The analysis of asphaltene aggregate adsorption onto biogenic $\mathrm{SiO}_{2}$ nanoparticles using a QCR and GPC-ICP-HR-MS analysis allowed the understanding of the nanoparticle effect and 
the role of the different size distribution aggregates on the asphaltene stability and deposition characteristics.

The QCR results show that biogenic $\mathrm{SiO}_{2}$ nanoparticles effectively adsorbs the most unstable asphaltenes, leading into an increase of the destabilization onset from $15 \mathrm{wt} \%$ to $66 \mathrm{wt} \%$ of nheptane composition for the remaining supernatant. A decrease in the deposited mass on the quartz surface was also observed until no deposit was detected.

There is not a significant amount of unstable asphaltenes detected by the QCR sensor for samples G-H, while the reduction of the GPC-ICP-HR-MS signal is incomplete for these samples with a total area that represents between $24-18 \%$ of the sulfur aggregates of the original asphaltenes. These factors suggest that the reduction in the deposition onto the quartz surface is not only due to a reduction of the total amount of asphaltenes, but that HMW aggregates play a major role in the asphaltene destabilization and deposition characteristics.

Recently, Taziketh et al..$^{53}$ reported that fewer and/or smaller agglomerates of asphaltenes precipitate, as determined via AFM, after asphaltene treatment with polythiophene-coated $\mathrm{Fe}_{3} \mathrm{O}_{4}$ nanoparticles. Our results confirm that nanoparticles not only reduce the amount of asphaltenes in solution but also decrease the size of the asphaltene aggregates in the remaining solution by adsorbing the most unstable and larger nanoaggregates.

Interestingly, the GPC-ICP MS Vanadium chromatogram of the samples G and H, with a signal starting from 1260s is very similar with the results reported in our previous works ${ }^{37+3}$, for acetone fraction, with a GPC-ICP MS chromatogram starting at 22.5min (1272s) and presenting 3 maximums $(23.2 \mathrm{~min}=1400 \mathrm{~s}, 25.5 \mathrm{~min}=1530 \mathrm{~s}$ and $28.5=1710 \mathrm{~s})$. This acetone fraction also showed a very low tendency to form deposit on the quartz surface, and the FT-ICR MS analysis proved that it presents a higher aromaticity and more island-like structure than the other fractions $\left(\mathrm{Hep} / \mathrm{Tol}\right.$ and Tol/THF/MeOH). Also, Putman et al ${ }^{3435}$, showed that the most abundant species in larger nanoaggregates are more aliphatic compounds, suggesting that London forces 
leads asphaltenes self-association. Thus, the results here suggest that nanoparticles interact with the more aliphatic archipelago-like compounds, presents in the larger nanoaggregates size distributions (sHMW and HMW), leaving in solution the smallest and more aromatic ones (MMW and LMW).

Figure 7 presents the slope of the variation of the deposited mass curve $(\mathrm{d} \Delta \mathrm{m})$ versus the composition of the system. This curve describes the growth rate of the asphaltene aggregates deposited on the QCR. With a simple calculation it's possible to estimate the mass quantity of asphaltenes deposited on the surface, assuming a typical asphaltene molecule with a molecular weight of 700 g.mol-1 with a nanoaggregate composed by 7 molecules and a size of $3 \mathrm{~nm}^{54}$, an approximation of the number of aggregates deposited on a square area corresponding to the nano aggregate size (9-nm² area), the mass deposited during each step of the titration can be estimate, the values are shown by the blue axis in Figure 7. At the beginning of the titration from composition of $15 \mathrm{wt} \% \mathrm{n}$-heptane and up to $40 \mathrm{wt} \%$, a constant number of nanoaggregates of approximately $0.7 \mathrm{a} . \mathrm{u}$. are deposited on this $9 \mathrm{~nm}^{2}$ area. After this composition, the number of aggregates increases significantly for solutions with more than $10 \% \mathrm{HMW}$ nanoaggregates (A-D) while, when the $\%$ of HMW is below $10 \%$, the number of aggregates adsorbed remain constant. This is because there is no formation of large aggregates in the solution, so the adsorbed mass shows linear growth with the composition.

At the beginning of the titration, only few nanoaggregates are adsorbed because the changes in this are occurring in the liquid. When formation of aggregates begins, the deposition leads to a significant growth in the adsorbed mass. An important observation of the obtained results is that once the large aggregates are extracted from the solution there is no formation of new large aggregates. As Figure 7 clearly shows, as the nanoparticles extract material from the solution, the deposition rate of molecules is slowed down, and further destabilization of the solution is required. 


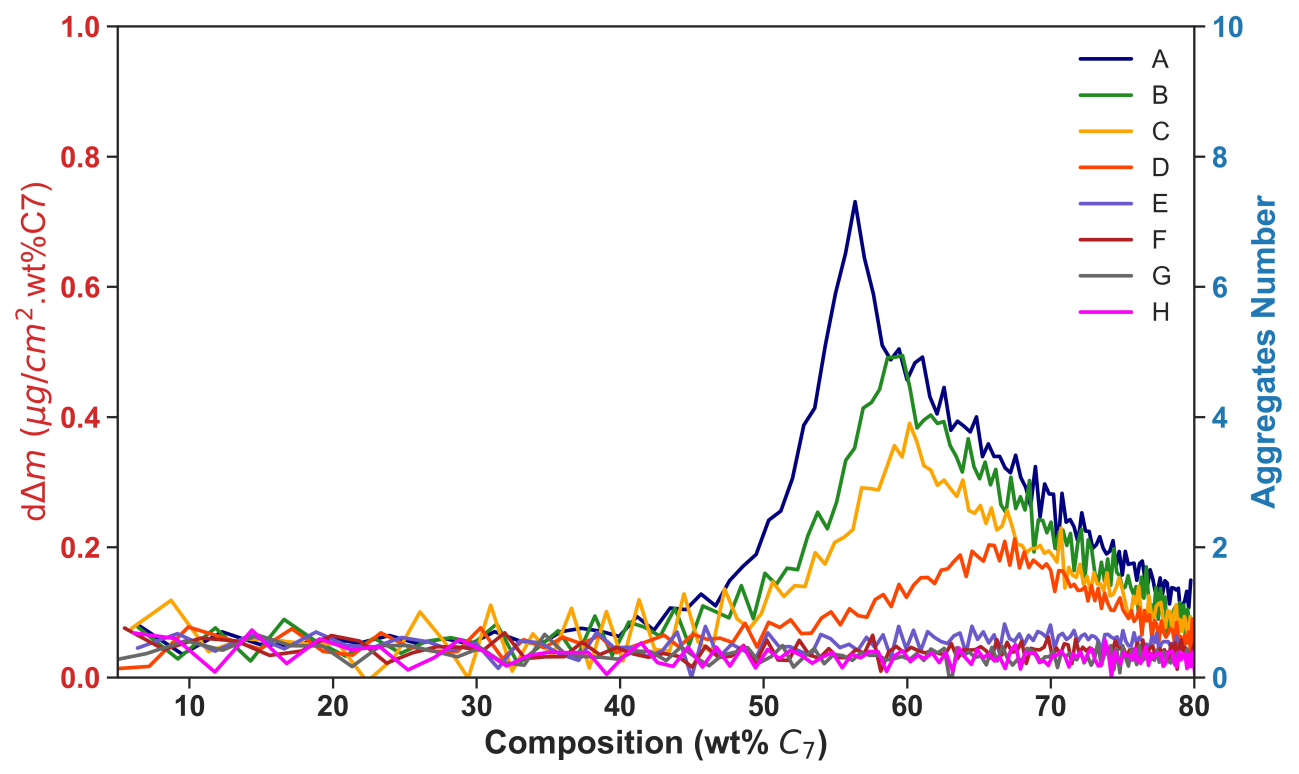

Figure 7. Deposited mass's slope $(\mathrm{d} \Delta \mathrm{m})$ vs. composition 


\section{CONCLUSIONS}

In this study, pure asphaltenes in toluene solutions were treated with biogenic $\mathrm{SiO}_{2}$ nanoparticles, and the remnants were analyzed via GPC-ICP HR-MS, destabilized using nheptane, and the aggregation and deposition processes were followed using a QCR sensor. Results show that biogenic $\mathrm{SiO}_{2}$ nanoparticles effectively remove the largest aggregates (sHMW and HMW) with no formation of new ones. The decrease of the amounts of sHMW and HMW nanoaggregates in the remnant's solutions enhanced stability and a decrease of the mass deposited on the QCR sensor after destabilization. Therefore, these size distributions play a major role in the asphaltene instability and deposition characteristics. The results show that the study of the absorption rate of the QCR sensor provides information about the type of destabilization.

\section{ASSOCIATED CONTENT}

Supporting Information

SI.1 - GPC Columns Calibration

SI Figure 1 - Calibration of the GCP columns. a) PS's molecular weight and elution times. b) Calibration curve.

SI.2 - Concentration of the remnant's solutions determined via UV-Vis.

SI Figure 2. Remnants solution's concentration obtained via UV-Vis. a) absorbance spectra of patron solutions. b) Calibration curve. c) absorbance spectra of remnants solutions. d) Concentration's values of remnants solutions.

SI.3 - Destabilization of remnants solutions with n-heptane followed by the QCR sensor. 
SI Figure 3. Destabilization curves for remnants solutions. Left) Frequency shifts of the 3rd harmonic $(\Delta \mathrm{f} 3)$ as a function of composition. Right) Theoretical deposited mass $(\Delta \mathrm{m})$ as a function of composition.

SI.4 - Decomposition treatment of the GPC-ICP MS chromatograms of vanadium and sulfur containing compounds and assignment in the different gaussians in the aggregates size distributions.

SI Figure 4. Gaussian fitting of the Sulfur (a) and Vanadium (b) GPC ICP MS chromatograms.

SI Figure 5. Gaussians fit and decomposition of the Sulfur GPC-ICP-HR-MS chromatograms for all samples.

SI Figure 6. Gaussians fit and decomposition of Vanadium GPC-ICP-HR-MS chromatograms for all samples.

\section{AUTHOR INFORMATION}

\section{*Corresponding Author}

Tel: $(+58) 2126051158$

Email: jimmy.castillo@ciens.ucv.ve

Tel: +33 (0) 559407752

Email: brice.bouyssiere@univ-pau.fr 


\section{Funding Sources}

\section{Notes}

The authors declare no competing financial interests.

\section{ACKNOWLEDGMENT}

The financial support provided by the Franco-Venezuelan Project RMR (Réseau Marcel Roche) is gratefully acknowledged. 


\section{REFERENCES}

(1) Speight, J. The Chemistry and Technology of Petroleum, Fourth Edition; 2006; Vol. 20064186. https://doi.org/10.1201/9781420008388.

(2) Alimohammadi, S.; Zendehboudi, S.; James, L. A Comprehensive Review of Asphaltene Deposition in Petroleum Reservoirs: Theory, Challenges, and Tips. Fuel 2019, 252 (May), 753-791. https://doi.org/10.1016/j.fuel.2019.03.016.

(3) Adams, J. J. Asphaltene Adsorption, a Literature Review. Energy and Fuels 2014, 28 (5), 2831-2856. https://doi.org/10.1021/ef500282p.

(4) Chacón-Patiño, M.L.; Rowland, S. M.; Rodgers, R. P.; Chacón-Patiño, M. L.; Rowland, S. M.; Rodgers, R. P. Advances in Asphaltene Petroleomics. Part 1: Asphaltenes Are Composed of Abundant Island and Archipelago Structural Motifs. Energy and Fuels 2017, 31 (12), 13509-13518. https://doi.org/10.1021/acs.energyfuels.7b02873.

(5) Chacón-Patiño, M. L.; Rowland, S. M.; Rodgers, R. P. Advances in Asphaltene Petroleomics. Part 2: Selective Separation Method That Reveals Fractions Enriched in Island and Archipelago Structural Motifs by Mass Spectrometry. Energy and Fuels 2018, 32 (1), 314-328. https://doi.org/10.1021/acs.energyfuels.7b03281.

(6) Chacón-Patiño, M. L.; Rowland, S. M.; Rodgers, R. P. Advances in Asphaltene Petroleomics. Part 3. Dominance of Island or Archipelago Structural Motif Is Sample Dependent. Energy and Fuels 2018, $32 \quad$ (9), 9106-9120. https://doi.org/10.1021/acs.energyfuels.8b01765.

(7) Shah, A.; Fishwick, R.; Wood, J.; Leeke, G.; Greaves, M. A Review of Novel Techniques for Heavy Oil and Bitumen Extraction and Upgrading. 2010, 700-714. https://doi.org/10.1039/b918960b. 
(8) Speight, J. G. Introduction to Enhanced Recovery Methods for Heavy Oil and Tar Sands; 2016. https://doi.org/10.1016/c2014-0-01296-8.

(9) Guo, K.; Li, H.; Yu, Z. In-Situ Heavy and Extra-Heavy Oil Recovery: A Review. Fuel 2016, 185, 886-902. https://doi.org/10.1016/j.fuel.2016.08.047.

(10) Mohd Afnan Ahmad; Samsuri, S.; Amran, N. A. Methods for Enhancing Recovery of Heavy Crude Oil, Processing of Heavy Crude Oils - Challenges and Opportunities. IntechOpen 2019, No. tourism, 13. https://doi.org/http://dx.doi.org/10.5772/57353.

(11) Melendez-Alvarez, A. A.; Garcia-Bermudes, M.; Tavakkoli, M.; Doherty, R. H.; Meng, S.; Abdallah, D. S.; Vargas, F. M. On the Evaluation of the Performance of Asphaltene Dispersants. Fuel 2016, 179, 210-220. https://doi.org/10.1016/j.fuel.2016.03.056.

(12) Mardani, E.; Mokhtari, B.; Soulgani, B. S. Comparison of the Inhibitory Capacity of Vegetable Oils, and Their Nonionic Surfactants on Iran Crude Oil Asphaltene Precipitation Using Quartz Crystal Microbalance. Pet. Sci. Technol.2018, 36 (11), 744749. https://doi.org/10.1080/10916466.2018.1445103.

(13) Madhi, M.; Kharrat, R.; Hamoule, T. Screening of Inhibitors for Remediation of Asphaltene Deposits: Experimental and Modeling Study. Petroleum 2018, 4 (2), 168177. https://doi.org/10.1016/j.petlm.2017.08.001.

(14) Alhreez, M.; Wen, D. Molecular Structure Characterization of Asphaltene in the Presence of Inhibitors with Nanoemulsions. RSC Adv. 2019, 9 (34), 19560-19570. https://doi.org/10.1039/c9ra02664a.

(15) Balestrin, L. B. D. S.; Francisco, R. D.; Bertran, C. A.; Cardoso, M. B.; Loh, W. Direct Assessment of Inhibitor and Solvent Effects on the Deposition Mechanism of 
Asphaltenes in a Brazilian Crude Oil. Energy and Fuels 2019, 33 (6), 4748-4757. https://doi.org/10.1021/acs.energyfuels.9b00043.

(16) Raj, G.; Larkin, E.; Lesimple, A.; Commins, P.; Whelan, J.; Naumov, P. In Situ Monitoring of the Inhibition of Asphaltene Adsorption by a Surfactant on Carbon Steel Surface. Energy \& Fuels 2019, $33 \quad$ (3), 2030-2036. https://doi.org/10.1021/acs.energyfuels.8b04246.

(17) Campen, S.; Moorhouse, S. J.; Wong, J. S. S. Mechanism of an Asphaltene Inhibitor in Different Depositing Environments: Influence of Colloid Stability. J. Pet. Sci. Eng. 2020, 184 (May 2019). https://doi.org/10.1016/j.petrol.2019.106502.

(18) Franco, C. A.; Nassar, N. N.; Ruiz, M. A.; Pereira-Almao, P.; Cortés, F. B. Nanoparticles for Inhibition of Asphaltenes Damage: Adsorption Study and Displacement Test on Porous Media. Energy and Fuels 2013, 27 (6), 2899-2907. https://doi.org/10.1021/ef4000825.

(19) Nassar, N. N.; Montoya, T.; Franco, C. A.; Cortés, F. B.; Pereira-Almao, P. A New Model for Describing the Adsorption of Asphaltenes on Porous Media at a High Pressure and Temperature under Flow Conditions. Energy \& Fuels 2015, 29 (7), 4210_ 4221. https://doi.org/10.1021/acs.energyfuels.5b00693.

(20) Betancur, S.; Carmona, J. C.; Nassar, N. N.; Franco, C. A.; Cortés, F. B. Role of Particle Size and Surface Acidity of Silica Gel Nanoparticles in Inhibition of Formation Damage by Asphaltene in Oil Reservoirs. Ind. Eng. Chem. Res. 2016, 55 (21), 6122-6132. https://doi.org/10.1021/acs.iecr.6b01187.

(21) Shojaati, F.; Riazi, M.; Mousavi, S. H.; Derikvand, Z. Experimental Investigation of the Inhibitory Behavior of Metal Oxides Nanoparticles on Asphaltene Precipitation. 
Colloids Surfaces A Physicochem. Eng. Asp. 2017, 531 (June), 99-110. https://doi.org/10.1016/j.colsurfa.2017.07.087.

(22) Varamesh, A.; Hosseinpour, N. Prediction of Asphaltene Precipitation in Reservoir Model Oils in the Presence of Fe3O4 and NiO Nanoparticles by Cubic Plus Association Equation of State. Ind. Eng. Chem. Res. 2019, 58 (10), 4293-4302. https://doi.org/10.1021/acs.iecr.8b05432.

(23) Azizkhani, A.; Gandomkar, A.; Azizkhami, A.; Gandomkar, A. A Novel Method for Application of Nanoparticles as Direct Asphaltenes Inhibitors during Miscible CO2 Injection. J. pe 2020, 185 (November 2019), 106661. https://doi.org/10.1016/j.petrol.2019.106661 .

(24) Tazikeh, S.; Sayyad Amin, J.; Zendehboudi, S. Experimental Study of Asphaltene Precipitation and Metastable Zone in the Presence of Polythiophene-Coated Fe3O4 $\begin{array}{llllll}\text { Nanoparticles. } & \text { J. } & \text { Mol. } & \text { Liq. } & 2020, & 301,\end{array}$ https://doi.org/10.1016/j.molliq.2019.112254.

(25) Marei, N. N.; Nassar, N. N.; Vitale, G.; Hassan, A.; Pérez Zurita, M. J. Effects of the Size of NiO Nanoparticles on the Catalytic Oxidation of Quinolin-65 as an Asphaltene Model Compound. Fuel 2017, 207, 423-437. https://doi.org/10.1016/j.fuel.2017.06.106.

(26) Zhou, K.; Zhou, X.; Liu, J.; Huang, Z. Application of Magnetic Nanoparticles in Petroleum Industry: A Review. J. Pet. Sci. Eng. 2020, 188 (January), 106943. https://doi.org/10.1016/j.petrol.2020.106943.

(27) Montes, D.; Henao, J.; Taborda, E. A.; Gallego, J.; Cortés, F. B.; Franco, C. A. Effect of Textural Properties and Surface Chemical Nature of Silica Nanoparticles from 
Different Silicon Sources on the Viscosity Reduction of Heavy Crude Oil. ACS Omega 2020, 5 (10), 5085-5097. https://doi.org/10.1021/acsomega.9b04041.

(28) Vargas, V.; Castillo, J.; Torres, R. .; Lienemann, C.-P.; Bouyssiere, B. Surface Modification of SiO2 Nanoparticles to Increase Asphaltene Adsorption. Pet. Sci. Technol. 2018, 6466. https://doi.org/10.1080/10916466.2018.1440300.

(29) Castillo, J.; Vargas, V.; Piscitelli, V.; Ordoñez, L.; Rojas, H. Study of Asphaltene Adsorption onto Raw Surfaces and Iron Nanoparticles by AFM Force Spectroscopy. $J$. Pet. Sci. Eng. 2017, 151 (October 2016), 248-253. https://doi.org/10.1016/j.petrol.2017.01.019.

(30) Giraldo, J.; Nassar, N. N.; Benjumea, P.; Pereira-Almao, P.; Cortés, F. B. Modeling and Prediction of Asphaltene Adsorption Isotherms Using Polanyi's Modified Theory. Energy and Fuels 2013, 27 (6), 2908-2914. https://doi.org/10.1021/ef4000837.

(31) Nassar, N. N.; Betancur, S.; Acevedo, S.; Franco, C. A.; Cortés, F. B. Development of a Population Balance Model to Describe the Influence of Shear and Nanoparticles on the Aggregation and Fragmentation of Asphaltene Aggregates. Ind. Eng. Chem. Res. 2015, 54 (33), 8201-8211. https://doi.org/10.1021/acs.iecr.5b02075.

(32) Castillo, J.; Vargas, V.; Gonzalez, G.; Ruiz, W.; Gascon, G.; Bouyssiere, B. Development of a Methodology by GPC-ICP HR MS for the Study of the Adsorption of Asphaltene Aggregates on SiO Nanoparticles. Energy and Fuels 2020. https://doi.org/10.1021/acs.energyfuels.0c00714.

(33) González, G.; Acevedo, S.; Castillo, J.; Villegas, O.; Ranaudo, M. A.; Guzmán, K.; Orea, M.; Bouyssiere, B. Study of Very High Molecular Weight Cluster Presence in THF Solution of Asphaltenes and Subfractions A1 and A2, by Gel Permeation 
Chromatography with Inductively Coupled Plasma Mass Spectrometry. Energy \& Fuels 2020. https://doi.org/10.1021/acs.energyfuels.0c02743.

(34) Putman, J.C.; Moulian, R.; Smith, D. F.; Weisbrod, C. R.; Chacón-Patiño, M. L.; Corilo, Y. E.; Blakney, G. T.; Rumancik, L. E.; Barrere-Mangote, C.; Rodgers, R. P.; Giusti, P.; Marshall, A. G.; Bouyssiere, B. Probing Aggregation Tendencies in Asphaltenes by Gel Permeation Chromatography. Part 2: Online Detection by Fourier Transform Ion Cyclotron Resonance Mass Spectrometry and Inductively Coupled Plasma Mass Spectrometry. Energy and Fuels 2020, 34 (9), 10915-10925. https://doi.org/10.1021/acs.energyfuels.0c02158.

(35) Putman, J.C.; Moulian, R.; Barrère-Mangote, C.; Rodgers, R. P.; Bouyssiere, B.; Giusti, P.; Marshall, A. G. Probing Aggregation Tendencies in Asphaltenes by Gel Permeation Chromatography. Part 1: Online Inductively Coupled Plasma Mass Spectrometry and Offline Fourier Transform Ion Cyclotron Resonance Mass Spectrometry. Energy \& Fuels 2020. https://doi.org/10.1021/acs.energyfuels.0c01522.

(36) Putman, J. C.; Gutiérrez Sama, S.; Barrère-Mangote, C.; Rodgers, R. P.; Lobinski, R.; Marshall, A. G.; Bouyssiere, B.; Giusti, P. Analysis of Petroleum Products by Gel Permeation Chromatography Coupled Online with Inductively Coupled Plasma Mass Spectrometry and Offline with Fourier Transform Ion Cyclotron Resonance Mass Spectrometry. Energy and Fuels 2018, $32 \quad$ (12), 12198-12204. https://doi.org/10.1021/acs.energyfuels.8b02788.

(37) Chacón-Patiño, M. L.; Moulian, R.; Barrère-Mangote, C.; Putman, J. C.; Weisbrod, C. R.; Blakney, G. T.; Bouyssiere, B.; Rodgers, R. P.; Giusti, P. Compositional Trends for Total Vanadium Content and Vanadyl Porphyrins in Gel Permeation Chromatography Fractions Reveal Correlations between Asphaltene Aggregation and Ion Production 
Efficiency in Atmospheric Pressure Photoionization. Energy and Fuels 2020. https://doi.org/10.1021/acs.energyfuels.0c03349.

(38) Ekholm, P.; Blomberg, E.; Claesson, P.; Auflem, I. H.; Sjöblom, J.; Kornfeldt, A. A Quartz Crystal Microbalance Study of the Adsorption of Asphaltenes and Resins onto a Hydrophilic Surface. J. Colloid Interface Sci. 2002, 247 (2), 342-350. https://doi.org/10.1006/jcis.2002.8122.

(39) Daridon, J.-L.; Cassiède, M.; Nasri, D.; Pauly, J.; Carrier, H. Probing Asphaltene Flocculation by a Quartz Crystal Resonator. Energy and Fuels 2013, 27 (8), 4639-4647. https://doi.org/10.1021/ef400910v.

(40) Tavakkoli, M.; Panuganti, S. R.; Vargas, F. M.; Taghikhani, V.; Pishvaie, M. R.; Chapman, W. G. Asphaltene Deposition in Different Depositing Environments: Part 1. Model Oil. Energy and Fuels 2014, $28 \quad$ (3), 1617-1628. https://doi.org/10.1021/ef401857t.

(41) Campen, S.; Smith, B.; Wong, J. Deposition of Asphaltene from Destabilized Dispersions in Heptane-Toluene. Energy and Fuels 2018, 32 (9), 9159-9171. https://doi.org/10.1021/acs.energyfuels.8b01887.

(42) Saidoun, M.; Palermo, T.; Passade-Boupat, N.; Gingras, J. P.; Carrier, H.; Daridon, J.L. Revisiting Asphaltenes Instability Predictions by Probing Destabiliztion Using a Fully Immersed Quartz Crystal Resonator. Fuel 2019, 251 (February), 523-533. https://doi.org/10.1016/j.fuel.2019.04.025.

(43) Acevedo, N.; Moulian, R.; Chacón-Patiño, M. L.; Mejia, A.; Radji, S.; Daridon, J. L.; Barrère-Mangote, C.; Giusti, P.; Rodgers, R. P.; Piscitelli, V.; Castillo, J.; Carrier, H.; Bouyssiere, B. Understanding Asphaltene Fraction Behavior through Combined Quartz 
Crystal Resonator Sensor, FT-ICR MS, GPC ICP HR-MS, and AFM Characterization.

Part I: Extrography Fractionations. Energy and Fuels 2020, 34 (11), 13903-13915. https://doi.org/10.1021/acs.energyfuels.0c02687.

(44) Goual, L.; Abudu, A. Predicting the Adsorption of Asphaltenes from Their Electrical Conductivity. Energy and Fuels 2010, $24 \quad$ (1), 469-474. https://doi.org/10.1021/ef900801n.

(45) Abudu, A.; Goual, L. Adsorption of Crude Oil on Surfaces Using Quartz Crystal Microbalance with Dissipation (QCM-D) under Flow Conditions. Energy \& Fuels 2009, 23 (3), 1237-1248. https://doi.org/10.1021/ef800616x.

(46) Subramanian, S.; Simon, S.; Gao, B.; Sjöblom, J. Asphaltene Fractionation Based on Adsorption onto Calcium Carbonate: Part 1: Characterization of Sub-Fractions and QCM-Measurements. Colloids Surfaces A Physicochem. Eng. Asp. 2016, 495, 136-148. https://doi.org/10.1016/j.colsurfa.2016.02.011.

(47) Kuang, W.; Saraji, S.; Piri, M. A Systematic Experimental Investigation on the Synergistic Effects of Aqueous Nanofluids on Interfacial Properties and Their Implications for Enhanced Oil Recovery. Fuel 2018, 220 (July 2017), 849-870. https://doi.org/10.1016/j.fuel.2018.01.102.

(48) Daridon, J.-L.; Carrier, H. Measurement of Phase Changes in Live Crude Oil Using an Acoustic Wave Sensor: Asphaltene Instability Envelope. Energy and Fuels 2017, 31 (9), 9255-9267. https://doi.org/10.1021/acs.energyfuels.7b01655.

(49) Joonaki, E.; Burgass, R.; Hassanpouryouzband, A.; Tohidi, B. Comparison of Experimental Techniques for Evaluation of Chemistries against Asphaltene Aggregation and Deposition: New Application of High-Pressure and High- 
Temperature

Quartz

Crystal

Microbalance.

2018.

https://doi.org/10.1021/acs.energyfuels.7b02773.

(50) Castillo, J.; Vargas, V.; Gonzalez, G.; Ruiz, W.; Bouyssiere, B. Evidence of Selective Asphaltene Subfraction Adsorption on $\mathrm{SiO} 2$ Nanoparticles Studied by UV-Vis Absorbance and Fluorescence Spectroscopy. J. Dispers. Sci. Technol. 2020, o (0), 1-7. https://doi.org/10.1080/01932691.2020.1845956.

(51) Caumette, G.; Lienemann, C. P.; Merdrignac, I.; Bouyssiere, B.; Lobinski, R. Fractionation and Speciation of Nickel and Vanadium in Crude Oils by Size Exclusion Chromatography-ICP MS and Normal Phase HPLC-ICP MS. J. Anal. At. Spectrom. 2010, 25 (7), 1123-1129. https://doi.org/10.1039/c003455j.

(52) Pohl, P.; Dural, J.; Vorapalawut, N.; Merdrignac, I.; Lienemann, C. P.; Carrier, H.; Grassl, B.; Bouyssiere, B.; Lobinski, R. Multielement Molecular Size Fractionation in Crude Oil and Oil Residue by Size Exclusion Microchromatography with High Resolution Inductively Coupled Plasma Mass Spectrometric Detection (HR ICP MS). J. Anal. At. Spectrom. 2010, 25 (12), 1974-1977. https://doi.org/10.1039/c0ja00076k.

(53) Marcano, F.; Flores, R.; Chirinos, J. J.; Ranaudo, M. A. Distribution of Ni and v in A1 and A2 Asphaltene Fractions in Stable and Unstable Venezuelan Crude Oils. Energy and Fuels 2011, 25 (5), 2137-2141. https://doi.org/10.1021/ef200189m.

(54) Tazikeh, S.; Sayyad Amin, J.; Zendehboudi, S.; Dejam, M.; Chatzis, I. Bi-Fractal and Bi-Gaussian Theories to Evaluate Impact of Polythiophene-Coated Fe3O4 Nanoparticles on Asphaltene Precipitation and Surface Topography. Fuel 2020, 272 (January), 117535. https://doi.org/10.1016/j.fuel.2020.117535. 
(55) Acevedo, S.; Castillo, J.; Vargas, V.; Castro, A.; Delgado, O.; Cortés, F. B.; Franco, C. A.; Bouyssiere, B. Suppression of Phase Separation as a Hypothesis to Account for Nuclei or Nanoaggregate Formation by Asphaltenes in Toluene. Energy and Fuels 2018, 32 (6), 6669-6677. https://doi.org/10.1021/acs.energyfuels.8b00949. 


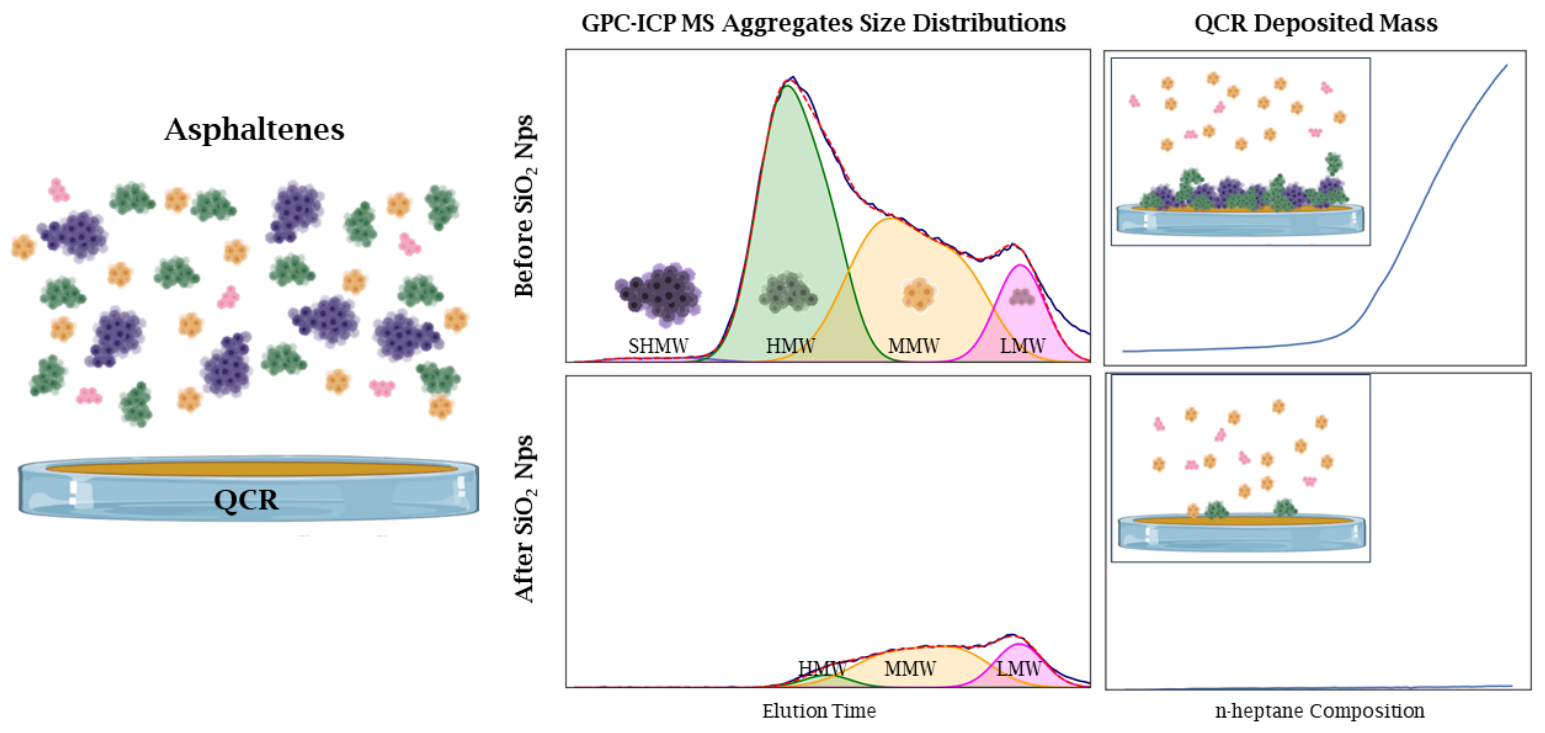




\section{TABLE CAPTIONS}

Table 1. Physical characteristics of $\mathrm{SiO}_{2}$ biogenic nanoparticles.

Table 2. Samples mass compositions and destabilization characteristics of remnants solutions determined with the QCR sensor. 


\section{TABLES}

Table 1. Physical characteristics of $\mathrm{SiO}_{2}$ biogenic nanoparticles.

Mean hydrodynamic diameter (nm) Specific surface (BET) $\left(\mathbf{m}^{2} \cdot \mathrm{g}^{-1}\right)$ 
Table 2. Samples mass compositions and destabilization characteristics of remnants solutions determined with the QCR sensor.

\begin{tabular}{|c|c|c|c|c|c|c|}
\hline \multirow[b]{2}{*}{ Sample } & \multicolumn{2}{|c|}{$\begin{array}{c}\text { Mass } \\
\text { Compositions }\end{array}$} & \multicolumn{4}{|c|}{ Remnants solution } \\
\hline & $\begin{array}{l}\mathrm{Nps} \\
\text { mass } \\
(\mathrm{mg} \\
\pm 1 \\
\mathrm{mg})\end{array}$ & NAMR & $\begin{array}{c}\text { Total } \\
\text { Concentration* } \\
(\mathrm{mg} / \mathrm{l})\end{array}$ & $\begin{array}{c}\text { V } \\
\text { Concentration }^{¥} \\
(\mathrm{mg} / \mathrm{Kg})\end{array}$ & $\begin{array}{c}\text { Destabilization } \\
\text { Onset } \\
\text { (wt\% n- } \\
\text { heptane) }\end{array}$ & $\begin{array}{c}\text { Deposited } \\
\text { Mass } \\
(\Delta \mathrm{m}) \\
\left(\mu \mathrm{g} . \mathrm{cm}^{-2}\right)\end{array}$ \\
\hline $\mathrm{A}$ & 0 & 0 & 604 & 2057 & 15 & 25.6 \\
\hline B & 30 & 2 & 508 & 1879 & 16 & 21.0 \\
\hline $\mathrm{C}$ & 75 & 5 & 361 & 1465 & 17 & 16.0 \\
\hline $\mathrm{D}$ & 150 & 10 & 220 & 1140 & 18 & 9.3 \\
\hline $\mathrm{E}$ & 225 & 15 & 146 & 926 & 20 & 3.3 \\
\hline $\mathrm{F}$ & 300 & 20 & 96 & 672 & 22 & 0.4 \\
\hline $\mathrm{G}$ & 450 & 30 & 51 & 497 & 49 & 0.0 \\
\hline $\mathrm{H}$ & 1050 & 70 & 33 & 377 & 66 & 0.0 \\
\hline
\end{tabular}

$\S$ Nanoparticles/ Asphaltenes Mass Ratio *Obtained via UV-Vis before titration $¥$ Calculated from the GPC-ICP MS profile area and using a V concentration of $2057 \mathrm{mg}$. $\mathrm{Kg}-1$ reported by Marcano et al. ${ }^{53}$ for this asphaltenes sample. 


\section{FIGURE CAPTIONS}

Figure 1. Experimental setup for n-heptane titration followed by the QCR sensor

Figure 2. n-Heptane titration of asphaltenes (Sample A) followed by the QCR sensor at $30^{\circ} \mathrm{C}$.

a) $\Delta \mathrm{f}_{3}$ vs $\Delta \Gamma_{3}$. b) Destabilization Onset (DO) estimation. c) Frequency shifts of the $3^{\text {r }}$ harmonic $\left(\Delta \mathrm{f}_{3}\right)$ as a function of composition. d) Theoretical deposited mass $(\Delta \mathrm{m})$ as a function of composition. Light blue area represents the stable zone with mass loading effect $=0$. Blue-gray area represents the unstable zone, with mass loading effect $<$ liquid loading effect. The purple area represents the unstable zone with mass loading effect $>$ liquid loading effect.

Figure 3. n-Heptane titration of diluted asphaltenes $(30 \mathrm{mg} / \mathrm{l})$ followed by the QCR sensor at $30^{\circ} \mathrm{C}$. A) $\Delta \mathrm{f}_{3}$ vs $\Delta \Gamma_{3}$. B) Destabilization onset (DO) estimation. C) Theoretical deposited mass comparison with samples A, F and G.

Figure 4. Sulfur- (a) and Vanadium-containing (b) compounds GPC-ICP HR MS chromatograms for asphaltenes solutions before (A) and after (B-H) adsorption onto $\mathrm{SiO}_{2}$ Bionanoparticles. sHMW, HMW, MMW, and LMW size distributions are separate by grey dashed lines.

Figure 5. Gaussians fit and decomposition into four size distributions (sHMW, HMW, MMW and LMW) of GPC-ICP-HR-MS (a) Sulfur- and (b) Vanadium-containing compounds chromatograms for Sample A (upper panel) and Sample H (lower panel). Vertical dotted lines define the border of the corresponding size distribution. 
Figure 6. Aggregates size distribution areas of ${ }^{32}$ Sulfur- (a) and ${ }^{51}$ Vanadium containing compounds (b) obtained with the Gaussian fitting for all samples. The green plot at the upper right panel, represent the variation of the two HMW families (HMW, and HMW ${ }_{2}$ ).

Figure 7. Deposited mass's slope $(\mathrm{d} \Delta \mathrm{m})$ vs. composition 


\section{FIGURES}
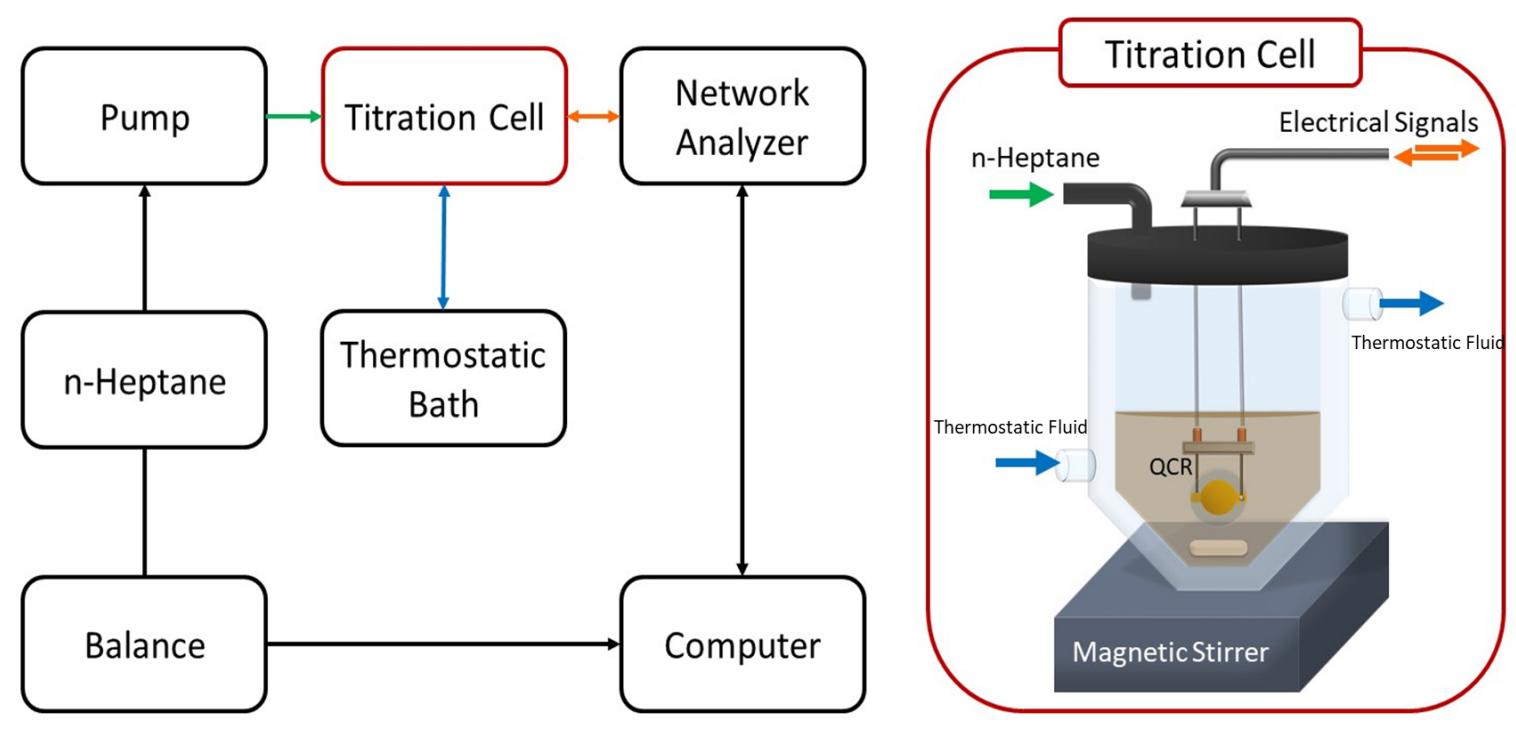

Figure 1. Experimental setup for n-heptane titration followed by the QCR sensor 

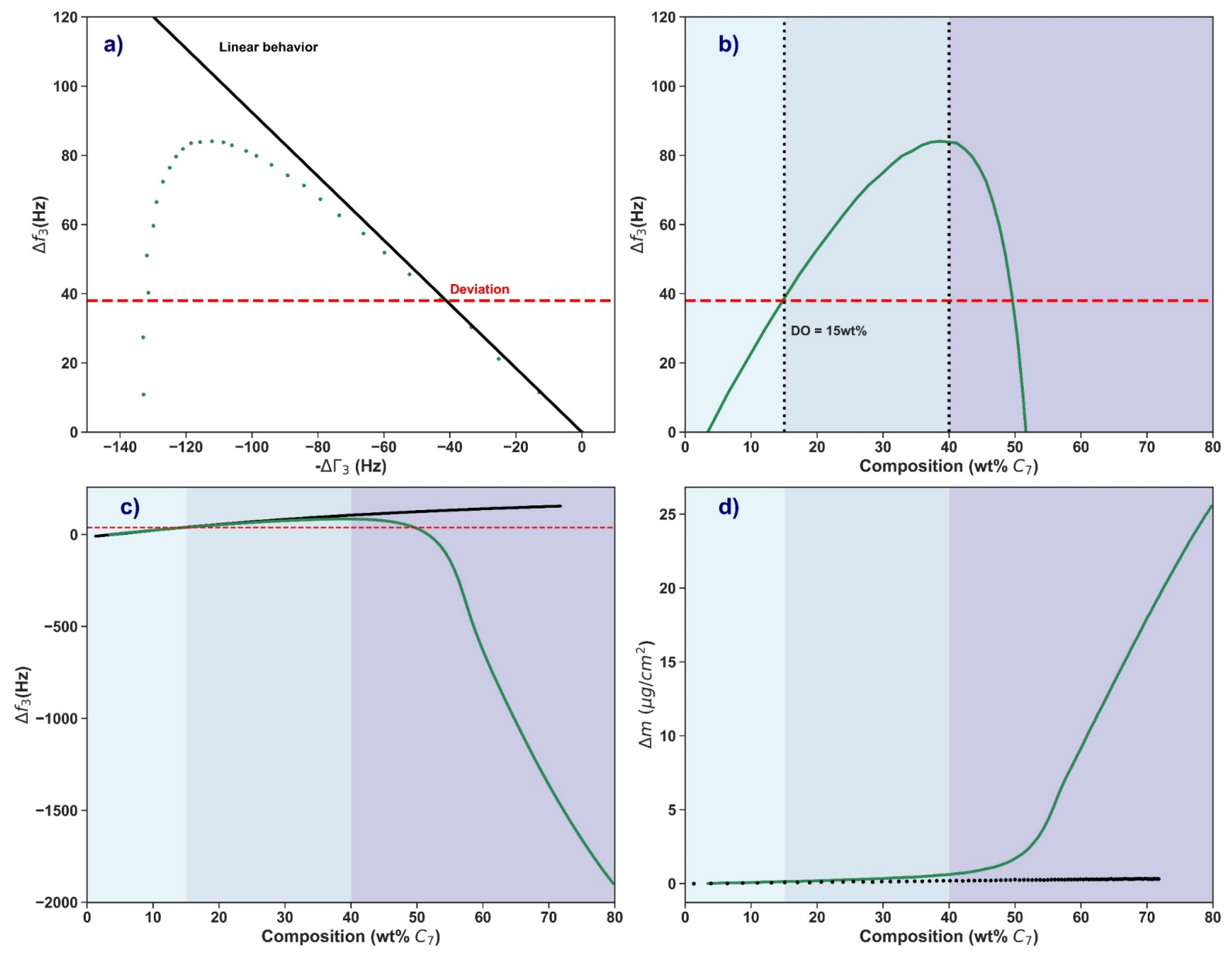

Figure 2. n-Heptane titration of asphaltenes (Sample A) followed by the QCR sensor at $30^{\circ} \mathrm{C}$.

a) $\Delta \mathrm{f}_{3}$ vs $\Delta \Gamma_{3}$. b) Destabilization Onset (DO) estimation. c) Frequency shifts of the $3^{\text {th }}$ harmonic $\left(\Delta \mathrm{f}_{3}\right)$ as a function of composition. d) Theoretical deposited mass $(\Delta \mathrm{m})$ as a function of composition. Light blue area represents the stable zone with mass loading effect $=0$. Blue-gray area represents the unstable zone, with mass loading effect < liquid loading effect. The purple area represents the unstable zone with mass loading effect $>$ liquid loading effect. 

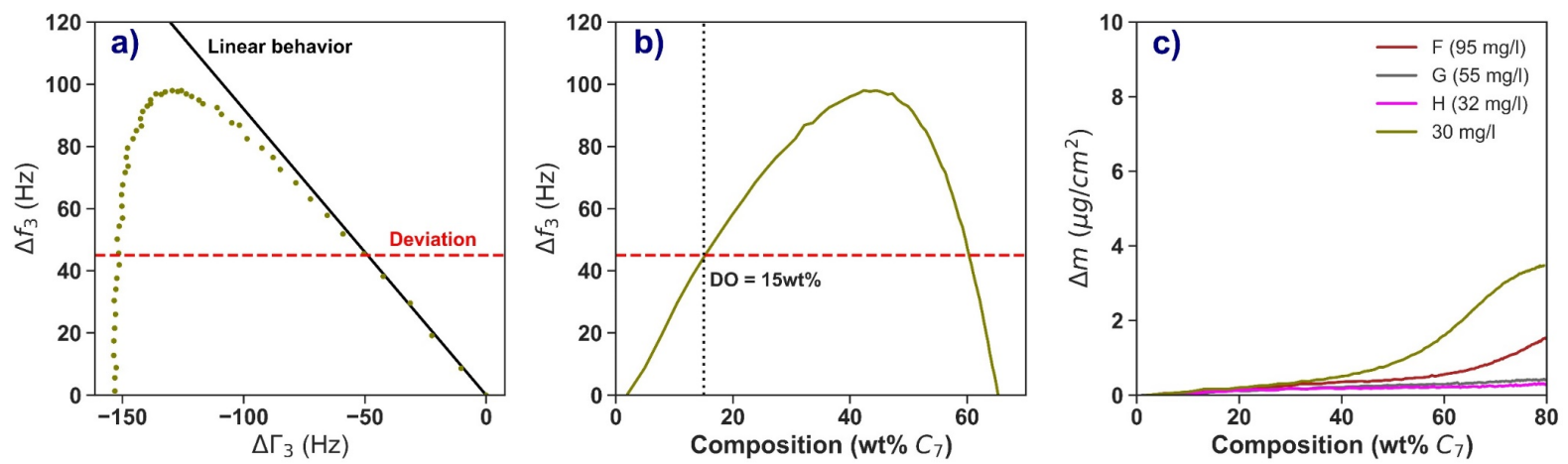

Figure 3. n-Heptane titration of diluted asphaltenes $(30 \mathrm{mg} / \mathrm{l})$ followed by the QCR sensor at $30^{\circ} \mathrm{C}$. A) $\Delta \mathrm{f}_{3}$ vs $\Delta \Gamma_{3}$. B) Destabilization onset (DO) estimation. C) Theoretical deposited mass comparison with samples A, F and G. 

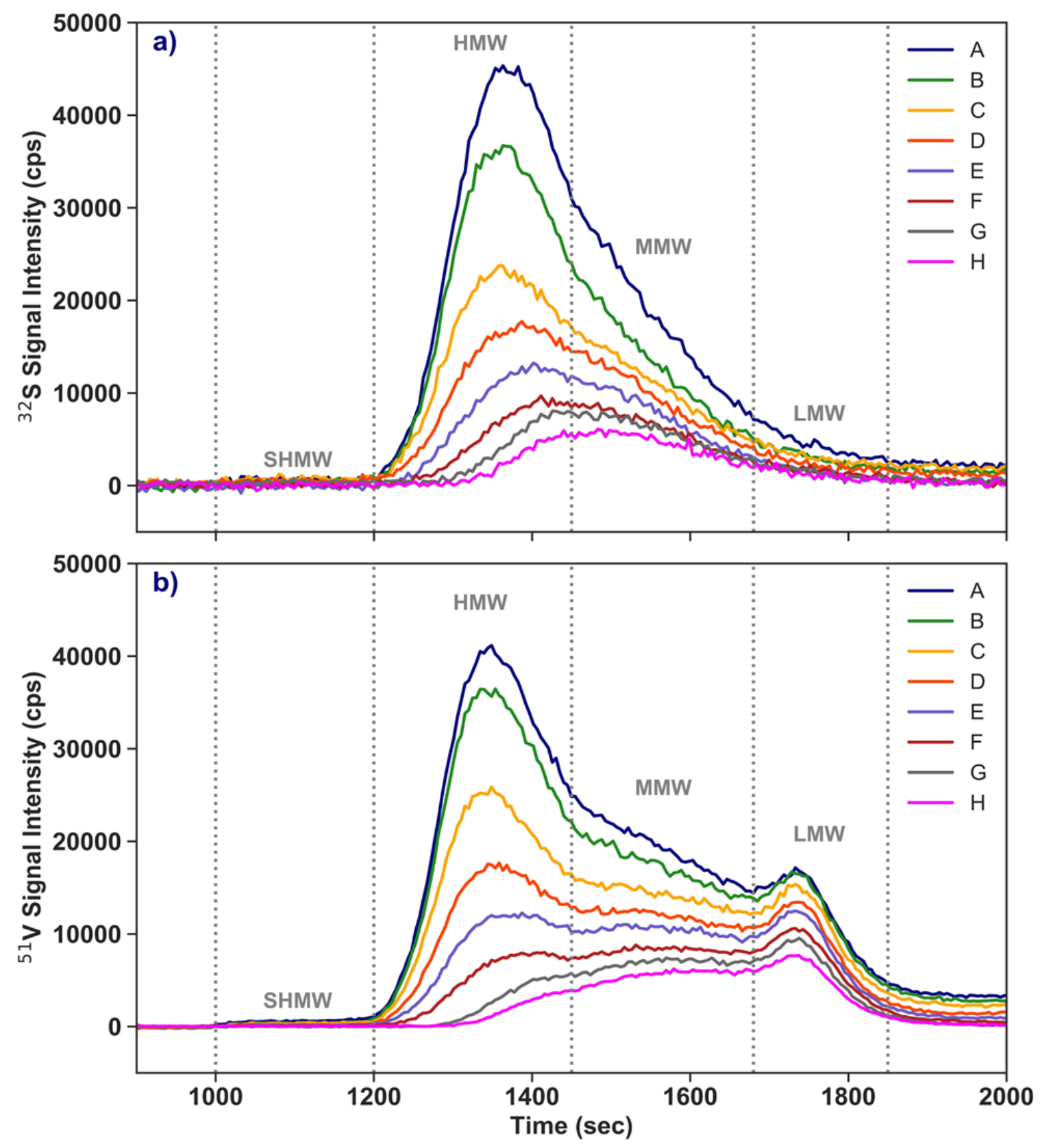

Figure 4. Sulfur- (a) and Vanadium-containing (b) compounds GPC-ICP HR MS chromatograms for asphaltenes solutions before (A) and after (B-H) adsorption onto $\mathrm{SiO}_{2}$ Bionanoparticles. sHMW, HMW, MMW, and LMW size distributions are separate by grey dashed lines. 

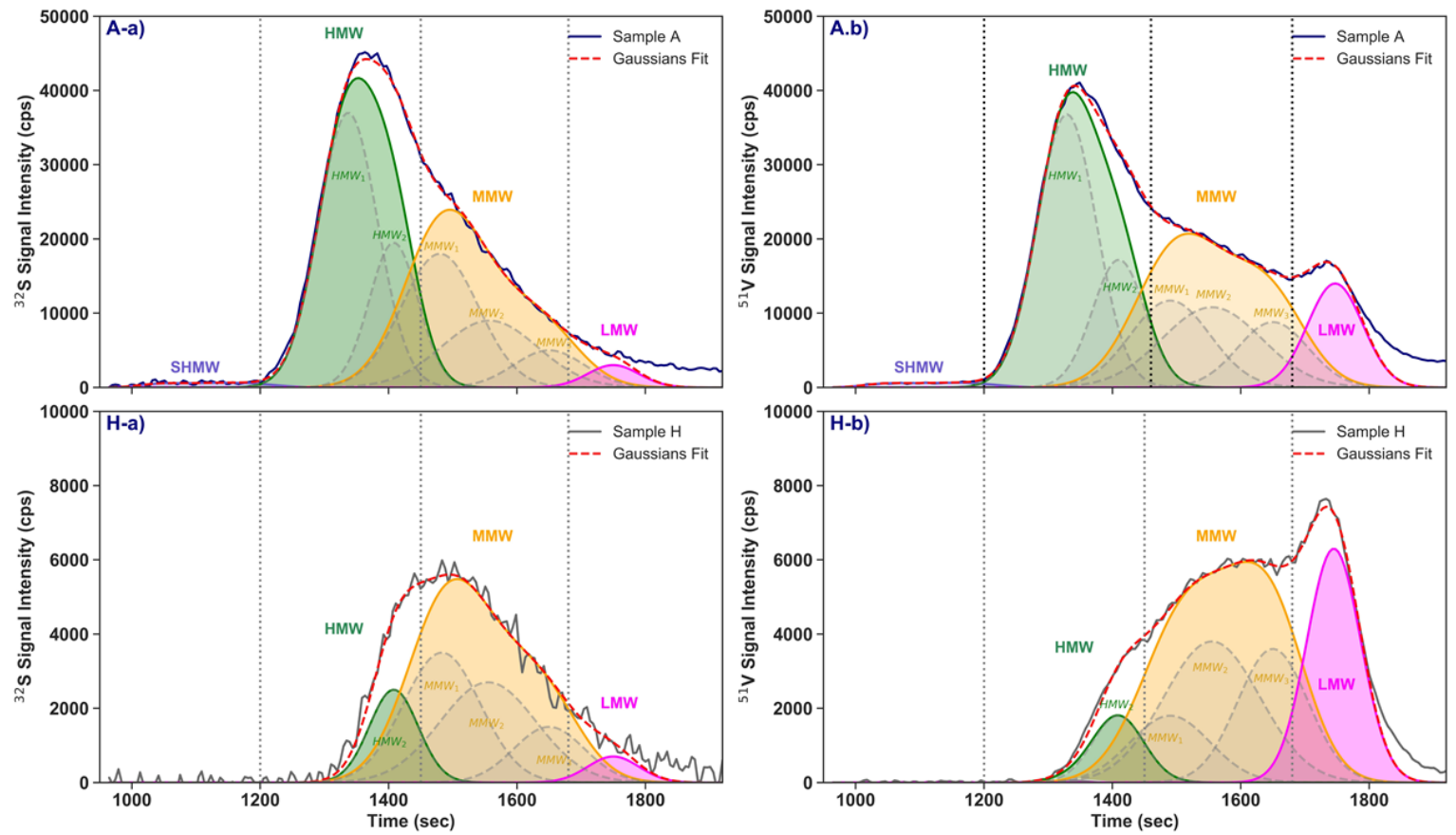

Figure 5. Gaussians fit and decomposition into four size distributions (sHMW, HMW, MMW and LMW) of GPC-ICP-HR-MS (a) Sulfur- and (b) Vanadium-containing compounds chromatograms for Sample A (upper panel) and Sample H (lower panel). Vertical dotted lines define the border of the corresponding size distribution. 
a)

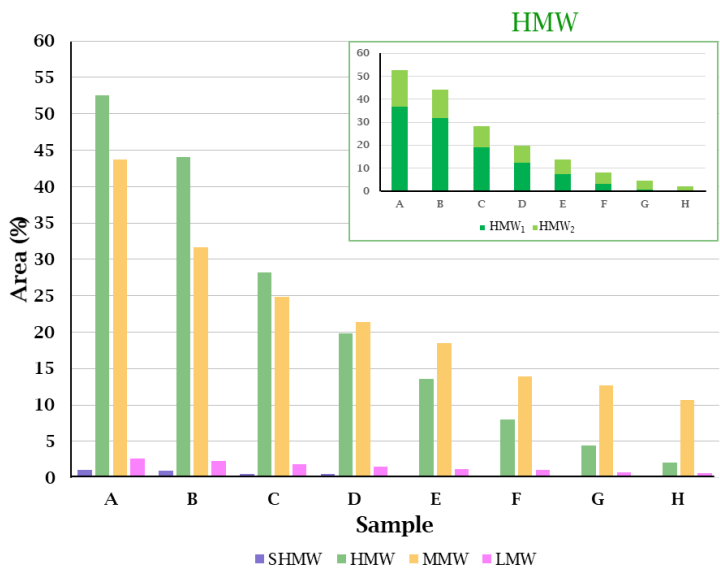

b)

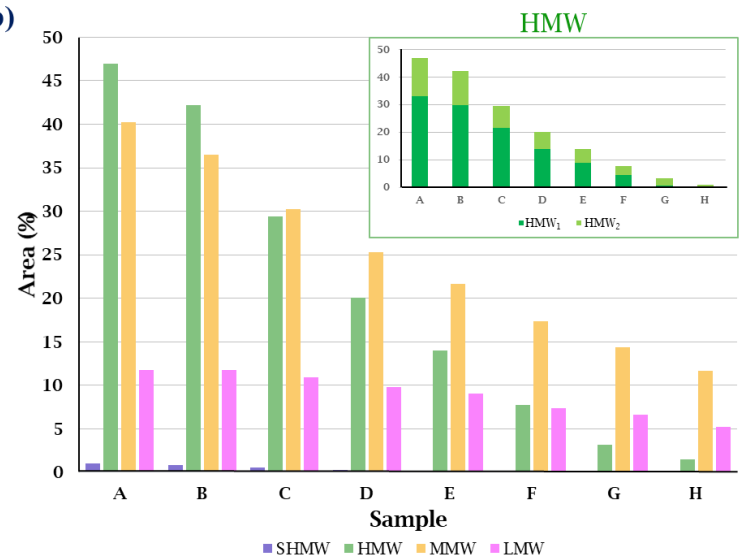

Figure 6. Aggregates size distribution areas of Sulfur- (a) and Vanadium containing compounds (b) obtained with the Gaussian fitting for all samples. The green plot at the upper right panel, represent the variation of the two HMW families (HMW and $\left.\mathrm{HMW}_{2}\right)$. 


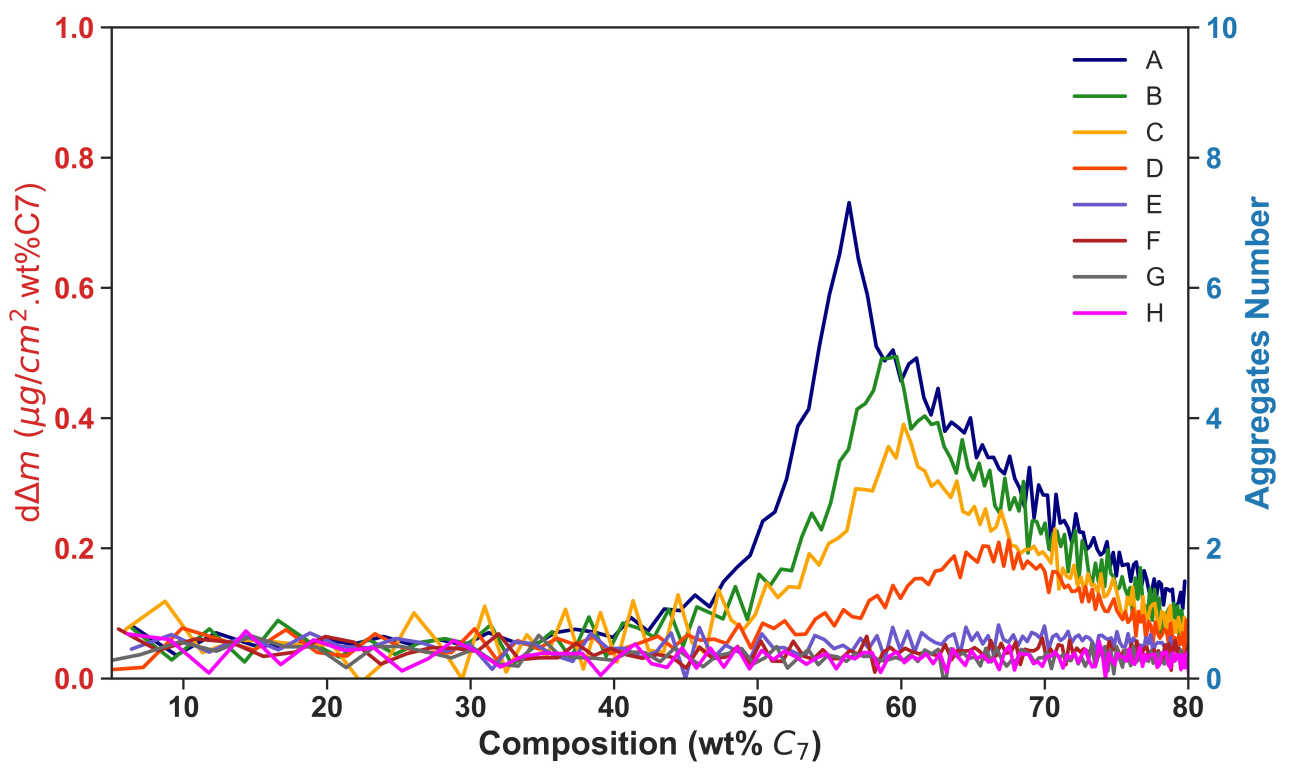

Figure 7. Deposited mass's slope (d $\Delta \mathrm{m})$ vs. composition 